\title{
March1 E3 Ubiquitin Ligase Modulates Features of Allergic Asthma in an Ovalbumin-Induced Mouse Model of Lung Inflammation
}

\author{
Osama A. Kishta $\left(\mathbb{D},{ }^{1}\right.$ Antoine Sabourin, ${ }^{1}$ Leora Simon, ${ }^{2}$ Toby McGovern $\left(\mathbb{D},{ }^{2}\right.$ \\ Maxime Raymond, ${ }^{1}$ Tristan Galbas, ${ }^{1}$ Abdelilah Majdoubi, ${ }^{1}$ Satoshi Ishido, ${ }^{3}$ \\ James G. Martin, ${ }^{2}$ and Jacques Thibodeau ${ }^{1}{ }^{1}$ \\ ${ }^{1}$ Université de Montréal, Laboratoire d'immunologie moléculaire, Département de microbiologie, Infectiologie et Immunologie, \\ Montreal, QC, Canada H3T $1 J 4$ \\ ${ }^{2}$ McGill University Health Center, Meakins-Christie Laboratories for Lung Research, Montreal, QC, Canada 4HA $3 J 1$ \\ ${ }^{3}$ Department of Microbiology, Hyogo College of Medicine, 1-1 Mukogawa-cho, Nishinomiya 663-8501, Japan
}

Correspondence should be addressed to Osama A. Kishta; osama.kishta@mail.mcgill.ca and Jacques Thibodeau; jacques.thibodeau@umontreal.ca

Received 1 December 2017; Accepted 8 February 2018; Published 3 May 2018

Academic Editor: Martin Holland

Copyright $\odot 2018$ Osama A. Kishta et al. This is an open access article distributed under the Creative Commons Attribution License, which permits unrestricted use, distribution, and reproduction in any medium, provided the original work is properly cited.

\begin{abstract}
Membrane-associated RING-CH-1 (March1) is a member of the March family of E3 ubiquitin ligases. March1 downregulates cell surface expression of MHC II and CD86 by targeting them to lysosomal degradation. Given the key roles of MHC class II and CD86 in T cell activation and to get further insights into the development of allergic inflammation, we asked whether March1 deficiency exacerbates or attenuates features of allergic asthma in mice. Herein, we used an acute model of allergy to compare the asthmatic phenotype of March1-deficient and -sufficient mice immunized with ovalbumin (OVA) and later challenged by intranasal instillation of OVA in the lungs. We found that eosinophilic inflammation in airways and lung tissue was similar between WT and March1 $1^{-1-}$ allergic mice, whereas neutrophilic inflammation was significant only in March $1^{-1-}$ mice. Airway hyperresponsiveness as well as levels of IFN- $\gamma$, IL-13, IL-6, and IL-10 was lower in the lungs of asthmatic March $1^{-/-}$mice compared to WT, whereas lung levels of TNF- $\alpha$, IL-4, and IL- 5 were not significantly different. Interestingly, in the serum, levels of total and ova-specific IgE were reduced in March1-deficient mice as compared to WT mice. Taken together, our results demonstrate a role of March1 E3 ubiquitin ligase in modulating allergic responses.
\end{abstract}

\section{Introduction}

Allergic asthma is a complex inflammatory disease, characterized by a Th2-skewed immune response [1]. Upon exposure of asthmatics to an allergen, antigen-presenting cells (APCs), such as dendritic cells (DCs) and macrophages, present peptides derived from the allergen to naïve $\mathrm{CD} 4 \mathrm{~T}$ lymphocytes in the context of MHC class II molecules (MHC II), followed by costimulatory signals delivered by CD86. Both MHC II and CD86 are targeted for ubiquitination by March1, a member of the membrane-associated RING-CH (March) family of E3 ubiquitin ligases [2, 3]. Ubiquitinated MHC II and CD86 are targeted for lysosomal degradation, thereby inhibiting these molecules from recycling on cell surface in the resting state $[2,4]$. Upon activation, March 1 expression in DCs and B lymphocytes is inhibited to increase the stability of MHC II on the cell surface and maximize antigen presentation to naïve $\mathrm{T}$ cells [5-7]. In line with these observations, IL-10, a potent antiinflammatory cytokine, stimulates March 1 expression and consequently downregulates expression of MHC II in human primary monocytes and mouse bone marrow-derived macrophages [8-10]. Further, March1-mediated MHC II ubiquitination is required for DCs to produce antigen-specific regulatory $\mathrm{T}$ cells [11], which in turn impair DC function ability to activate CD4 T cells in an IL-10/March1-dependent 
manner [12]. These studies suggest that March1 may attenuate allergic reactions in vivo.

Paradoxically, bone marrow-derived conventional DCs (cDCs) from March1-deficient mice presented OVA peptide to naïve CD4 T cells in vitro efficiently, but their ability to activate CD4 $\mathrm{T}$ cells was significantly reduced compared to cDCs from March1-sufficient mice. This suppression was attributable to loss of MHC II (and not CD86) ubiquitination [7]. Moreover, Th1/Th17 differentiation of naïve CD4 T cells was inhibited when they were cocultured with March1deficient cDCs [7]. According to these studies and considering the impact of $\mathrm{MHCII} /$ costimulators signals strength in $\mathrm{T}$ cell polarization [13], March1 deficiency may lead to impaired immune responses and modulate subsequent asthmatic features of allergy. Whether March1 deficiency attenuates, exacerbates, or modulates allergic lung inflammation in an in vivo model remains elusive. Thus, we assessed the responses of March1-deficient mice to sensitization and challenge with an allergen. More specifically, we addressed whether allergic lung inflammation, airway hyperresponsiveness, downstream cytokine profile, and mucus production were affected by March1 deficiency in vivo in a murine model of allergic asthma. Our results demonstrate that March1 deficiency leads to lung neutrophilic inflammation, in parallel with eosinophilia. It also reduces airway hyperresponsiveness as well as IL-13, IL-10, and IL-6 production, while it has no effect on OVA-induced eosinophilic lung inflammation, and mucus production.

\section{Material and Methods}

2.1. Mice. Colonies of wild-type C57BL/6J and March1deficient mice (on a C57BL/6 background) [4] were maintained in our facility. All procedures were approved by the Université de Montréal Animal Use Committee according to the Canadian guidelines for animal care and use.

2.2. Ovalbumin (OVA) Model of Allergy. Allergic asthma was induced as described previously [14] with slight modifications in route and amount of allergen [15]. Briefly, female mice (6-10 weeks) were sham sensitized by intraperitoneal injection with $150 \mu \mathrm{l}$ of sterile PBS or sensitized with $40 \mu \mathrm{g}$ OVA (purity $\geq 98 \%$, Sigma-Aldrich cat. number A5503-1G) adsorbed to $2 \mathrm{mg}$ Imject $^{\mathrm{TM}}$ Alum adjuvant (Thermo Fisher Scientific) in $150 \mu \mathrm{l} \mathrm{PBS}$ on day 0 and 7 . Then, all mice were challenged with OVA (100 $\mu \mathrm{g}$ in $40 \mu \mathrm{l} \mathrm{PBS})$ intranasally under isoflurane anesthesia on days 14,15 , and 16 . Mice were studied $24 \mathrm{~h}$ after the last challenge. Four experimental groups were studied: WT(sal-ova), WT(ovaova), March1 ${ }^{-/-}$(sal-ova), March1 ${ }^{-/-}$(ova-ova).

2.3. Lung Cell Harvest and Flow Cytometry. On day 17, mice were euthanized with $\mathrm{CO}_{2}$. Lungs were removed and the right lobe was digested with collagenase D (Roche Diagnostics), as described before [16]. For intracellular staining, the whole lungs were digested with collagenase to ensure that sufficient numbers of cells were collected. Briefly, lungs were chopped into small pieces with scissors, immersed in $5 \mathrm{~mL}$ of collagenase D (200 unit/mL), $\mathrm{Ca}^{2+}$ and $\mathrm{Mg}^{2+}$, DNAase, and incubated at $37^{\circ} \mathrm{C}$ with shaking for $60 \mathrm{~min}$. Cells were passed through $70 \mu \mathrm{m}$ pore mesh and washed once with PBS. Red blood cells were lysed with ammonium chloride. For surface marker staining, equal numbers of cells were incubated with survival stain (Zombie AquaTM, Biolegend) for $15 \mathrm{~min}$. Cells were incubated with $20 \mu \mathrm{l}$ of rat serum on ice for $15 \mathrm{~min}$ to prevent nonspecific binding. Cells were then stained with various fluorochrome-conjugated antibody cocktails for $35 \mathrm{~min}$ and analyzed by flow cytometry on a FacsCanto II (BD Biosciences, CA). For intracellular staining of cytokines, $1.5-2 \times 10^{6}$ cells per mouse were incubated at $37^{\circ} \mathrm{C}$ with cell activation cocktail (brefeldin A, PMA, and ionomycin; Biolegend) for $3.5 \mathrm{~h}$. Cells were then washed and stained for survival with Zombie Aqua stain, as described above. Cells were surface stained for CD45 and CD4, washed, fixed with $4 \%$ formalin for $20 \mathrm{~min}$ on ice in the dark, washed once with PBS $0.1 \%$ BSA, and kept overnight at $4^{\circ} \mathrm{C}$. Cells were then permeabilized with $0.2 \%$ saponin, stained with antiIL-5 (PE), anti-IL-13 (PE-Cy7), and anti-IFN $\gamma$ (APC) for $40 \mathrm{~min}$, washed twice with in PBS $0.2 \%$ saponin, and analyzed by flow cytometry.

2.4. Antibodies. Antibodies from BD Biosciences: PEanti-Siglec F (E50-2440), PE-Cy7-anti-CD19 (6D5), Percp 5,5-anti-CD11b (M1701), PE-anti-IL-5 (TRFK5), and APCanti-IFN- $\gamma$ (XMG1.2).

Antibodies from Biolegends: APC-anti-Ly6G (1A8), PE-CY7-anti-CD11c (HL3), BV421-anti-CD45 (30-F11), PE-anti-CD88, CR5a (20/70), and Alexa-fluor anti-I-A/IE, MHC II (M5/114.15.2).

2.5. Lung Cytokine Measurement. Left lobes were frozen and homogenized in RIPA buffer containing protease inhibitors, spun at $10000 \mathrm{rpm}$ for $5 \mathrm{~min}$ to remove debris, and supernatants were used to measure cytokines. The enhanced sensitivity cytometric bead array (CBA; BD Biosciences) was used following the manufacturer's instructions.

2.6. T Cell Stimulation Assay. Spleens were harvested aseptically, crushed in RPMI medium, and red blood cells were lysed in ammonium chloride. Cells were washed, resuspended in complete medium, and counted. Splenocytes were cultured in 96-well plate at $10^{6}$ cells/well in $200 \mu \mathrm{L}$ with OVA $(1 \mathrm{mg} / \mathrm{mL})$ or with medium alone for 3 days. Supernatants were then collected and frozen for later measurement of cytokines. Flex set CBA (BD Biosciences) was used following the manufacturer's instructions.

2.7. Dosage of Immunoglobulins. Total IgE and ova-specific IgE and IgG1 were measured in serum samples using commercial ELISA assays (eBiosciences), following the manufacturer's instructions.

2.8. Airway Hyperresponsiveness and Lung Lavage. On dedicated sets of mice, airway responsiveness to methacholine challenge was studied, as described previously [17]. Briefly, mice were anaesthetized and trachea was gently exposed. A blunt $18 \mathrm{G}$ needle was inserted in the trachea, secured and connected to flexiVent system. Methacholine provocation testing was performed. Respiratory system resistance was 
estimated using flexiVent software and the results were expressed as \% of the baseline values. Mice were then killed by overdose of anesthesia and lungs were lavaged with $1 \mathrm{~mL}$ of PBS containing $0.1 \%(w / v)$ BSA.

2.9. Histology. On separate sets of mice, lungs were lavaged with $1 \mathrm{~mL}$ of PBS ( $0.1 \% \mathrm{BSA})$, then flushed with PBS, inflated with, and then immersed in 10\% formalin for at least $24 \mathrm{~h}$ before embedding into paraffin blocks. Sections $(4 \mu \mathrm{m})$ were cut and Periodic Schiff Assay (PAS) staining of mucin was performed for evaluating mucus production $[18,19]$. The slides were cover slipped and scanned using ScanScope ${ }^{\circledR}$ AT Turbo technology (Leica Biosystems Inc., CA USA) at $40 \mathrm{x}$ magnification. Lung sections were viewed digitally using Aperio ImageScope. Mucus positive cells were counted along the circumference of 2-3 airway sections. Circumference of these airway sections was measured using ImageJ software. Mucus cells were expressed as number of cells/ $\mu \mathrm{m}$ of airway circumference and the values of the captured sections from the same mouse were averaged.

Lung lavage samples, collected following airway hyperresponsiveness tests or before fixing lungs for histology, were

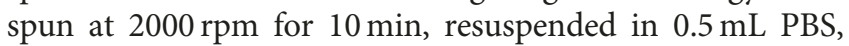
counted on hemacytometer using trypan blue exclusion, and expressed as total cells/mouse BAL. Fifty $\mu \mathrm{l}$ of each sample cells were adhered on slides using cytospin. Slides were then dried, fixed, and stained for differential count using HEMA 3 staining solutions (Fisher Scientific) as per the manufacturer's instructions. Cells $(200-300)$ were counted under a light microscope (40x) based on the morphology of different leukocytes.

2.10. Statistical Analysis. Normally distributed data are presented as mean with standard error, whereas nonparametric data are presented as median with interquartile values. Difference between two groups in normally distributed data was analyzed by student's $t$-test, whereas the Mann-Whitney $U$ test was used to analyze the difference between nonparametric data. A two-way ANOVA test was used to compare lung tissue inflammatory cells and airway resistance of all the experimental groups at each dose separately (fixed dose per test) considering strain and immunization factors. Airway resistance was also compared between ova-ova groups in the two strains (WT versus March1 KO) over the doses of methacholine challenge using two-way repeated measure ANOVA test, followed by Holm-Sidak tests for all pairwise multiple comparisons. A $p$ value $<0.05$ was considered statistically significant. ${ }^{*} p<0.05,{ }^{* *} p<0.01$, and ${ }^{* * *} p<0.001$. SigmaPlot V 11.0 was used to perform the statistical analysis and GraphPad Prism software was used for graphical plotting of data.

\section{Results}

In C57BL/6 mice, the OVA-induced acute model of allergy is characterized by Th2-driven pulmonary eosinophilic inflammation, elevated OVA-specific IgE and IgG1 as well as airway hyperresponsiveness [20]. However, some of these features and downstream levels of inflammatory mediators may vary depending on the dose of OVA used for sensitization as well as on the timing, dose, and method of challenge with the allergen [21]. Herein, we have compared these parameters between WT and March $1^{-1-}$ mice sensitized by two i.p. injections of ova-alum complex followed by a challenge regimen consisting of 3 daily OVA nasal instillations starting on day 14 , as described before $[14,15]$. These mice are referred below as "ova-ova" and were compared to control mice, which received saline instead of OVA-Alum complex for the two i.p. injections. These sham-sensitized mice are referred to as "sal-ova" throughout the paper.

3.1. March1 Is Expressed in the Lung. According to the initial characterization of the March family members' tissue expression reported by Bartee et al. [22], March1 is mostly found in lymph nodes and spleen, followed by the lung. However, there are no reliable monoclonal antibodies capable of detecting this protein in primary cells and this last study relied on the mRNA abundance. As March1 mRNA is predominantly found in immature DCs, macrophages and B lymphocytes, we verified that it is indeed functional in lung hematopoietic cells using flow cytometry to monitor MHC class II expression. The gating strategy used to analyze single-cell lung suspensions from WT and March $1^{-1-}$ mice is shown in Figure 1(a). First, we observed that MHC class II levels are higher in the bulk of $\mathrm{CD}_{4} 5^{+}$cells, independent of their expression of CD11b (Figures 1(b) and 1(c)). Then, we verified if MHC II expression could be modulated following exposure of immunized mice to ovalbumin in our model. MHC II surface expression was evaluated in lungs of shamsensitized and challenged (sal-ova) as well as in sensitized and challenged (ova-ova) mice from both strains. Although MHC II surface expression was higher in $\mathrm{CD}_{4} 5^{+}, \mathrm{CD} 11 \mathrm{~b}^{+}$, $\mathrm{CD}_{11 \mathrm{~b}^{-}}$, DCs, and B lymphocyte populations from lungs of $\mathrm{March}^{-1-}$ as compared to WT mice, this increase was independent from immunization conditions (Figure 1(d)).

\subsection{March1 Dampens Airway and Lung Neutrophilic} Inflammation in Allergic Asthma without Affecting Eosinophilia. Airway and lung inflammation, characterized by the predominant accumulation of eosinophils is considered one of the hallmarks of allergic asthma in C57BL/6 [23]. We show that in airways, the OVA challenge of immunized mice induced a strong rise in total inflammatory cells, both in WT and March $1^{-1-}$ mice (Table 1). However, this increase was more prominent in $\mathrm{March}^{-/-}(p<0.001)$ and tending to be higher in WT mice $(p<0.1)$. These cells were further characterized to identify various subpopulations based on their morphology. We found that eosinophils in airways of immunized and challenged groups (ova-ova) were significantly higher relative to their sham-immunized and challenged controls (sal-ova) in both strains, without significant difference between the March1-deficient and -sufficient mice. Neutrophils were higher in airways (BAL) of ova-ova relative to sal-ova within $\mathrm{March}^{-1-}$ but not WT (Table 1). In both strains, lymphocytes were higher in ova-ova, relative to sal-ova $(p<0.1$, Table 1$)$. The more prominent neutrophilic cellular count in ova-ova March $1^{-/-}$ 


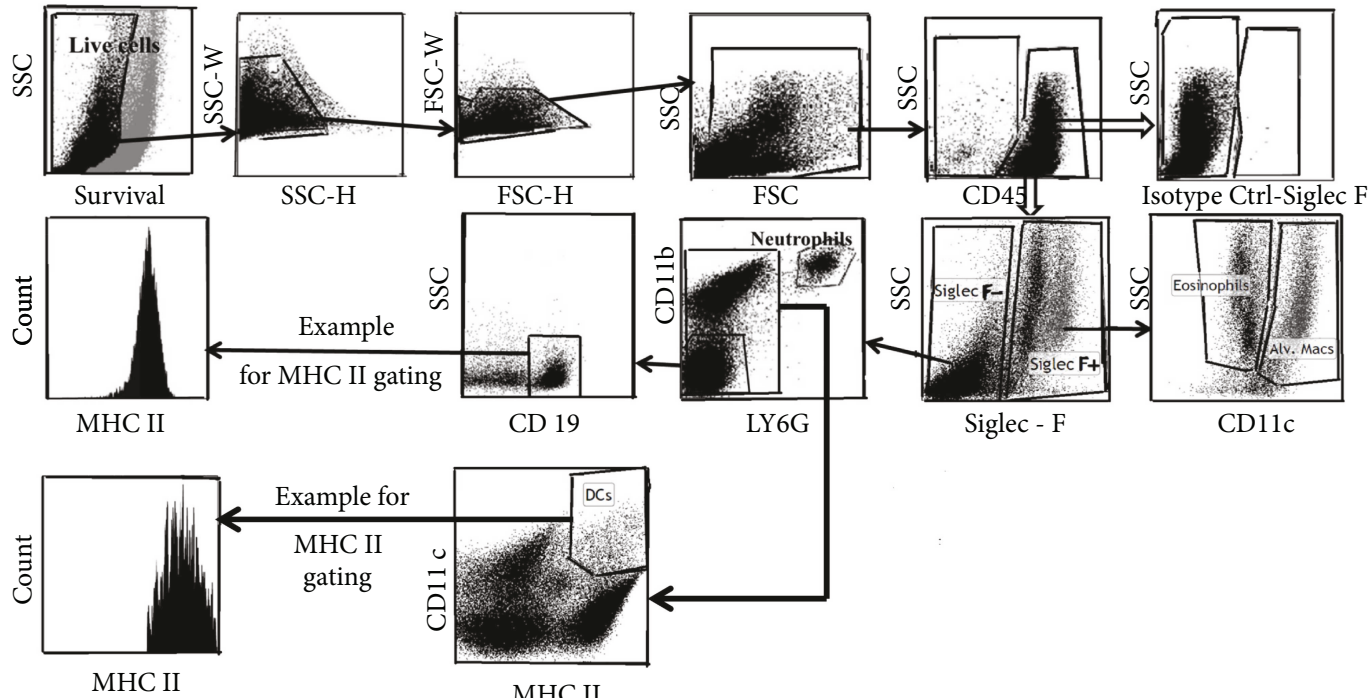

(a)

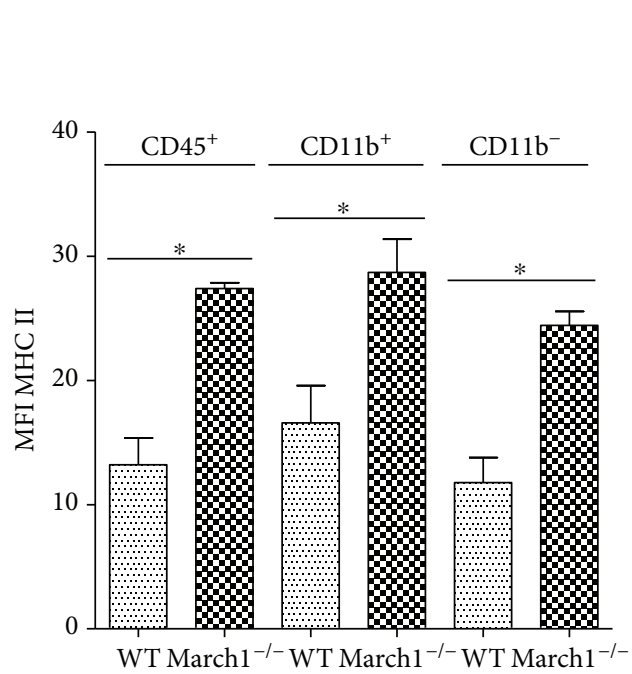

(c)

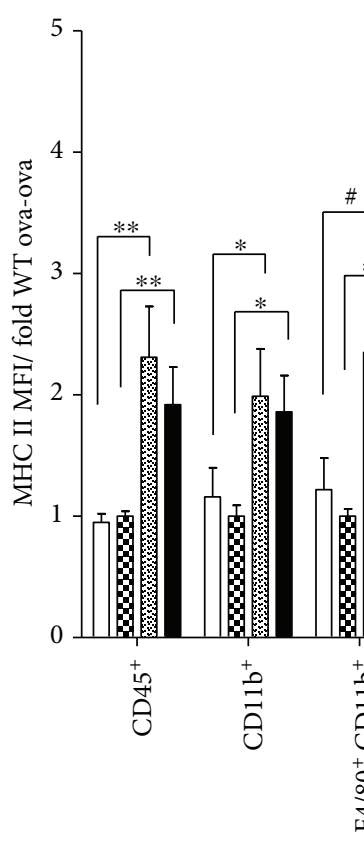

$\square$ sal-ova WT
ova-ova WT

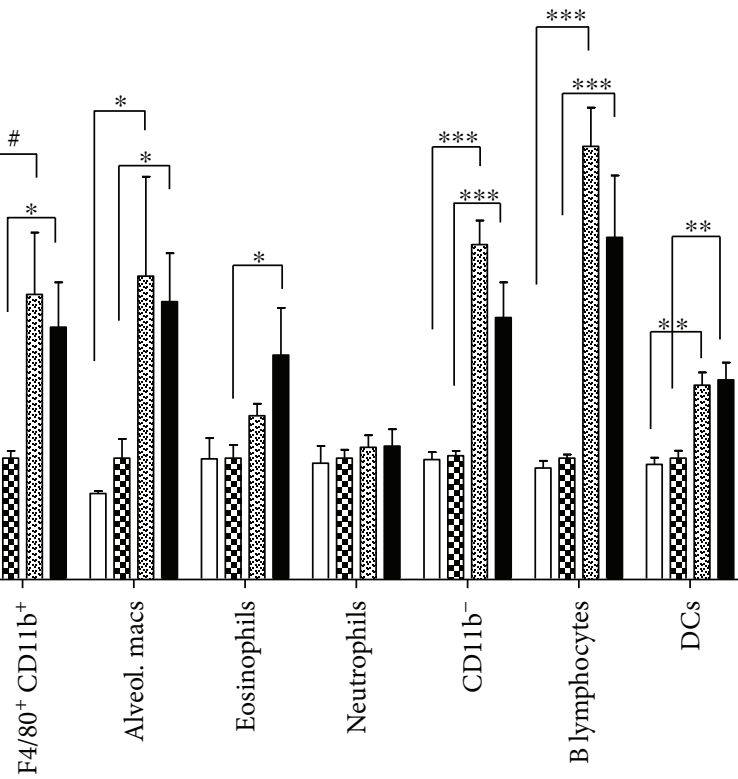

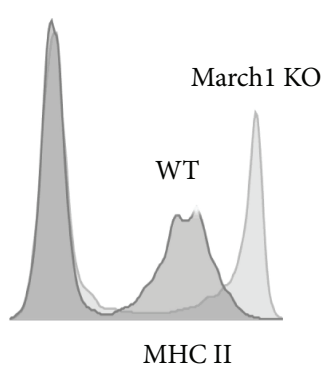

(b)

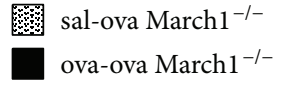

(d)

FIGURE 1: Deficiency of MARCH1 in $\mathrm{MARCH}^{-/-}$mice upregulates MHC II surface expression in lung myeloid and lymphoid immune cells. (a) Gating strategy illustrating analysis of the isolated and stained lung immune cells by flow cytometry for MHC II MFI assessment. (b) A representative comparison of MHC class II expression on WT and March $1^{-1-}$ CD11b-negative cells is shown. (c) MHC class II MFI of lung cells from WT and March1 $1^{-1-}$ mice. (d) MHC class II MFI of lung cells from WT and March1 ${ }^{-1-}$ mice in OVA-induced allergic model. For each population, MFIs were normalized to the value obtained for WT mice sensitized and challenged with OVA. ${ }^{*} p<0.05$, ${ }^{* *} p<0.01,{ }^{* * *} p<0.001$, and ${ }^{\#} p<0.1$ (trend). Data are presented as means with SEM; $n=4$ /group in (c) (one experiment); data are pooled from 4 independent experiments in (d), total $n=8$-9/group.

mice suggests that neutrophilic inflammation contributes to the relatively higher BAL cellularity in the $\mathrm{March}^{-/-}$ ova-ova group.

To determine if the immune cell accumulation in BAL is accompanied by a similar increase in the tissue, lungs were analyzed by flow cytometry. Eosinophils $\left(\mathrm{CD} 45^{+}\right.$SiglecF ${ }^{+}$
CD11 ${ }^{-}$), neutrophils (CD45 Siglec $\mathrm{F}^{-} \mathrm{CD}^{+} 1 \mathrm{~b}^{+} \mathrm{Ly}_{6 \mathrm{G}}^{+}$), and alveolar macrophages $\left(\mathrm{CD} 45^{+}\right.$Siglec $\mathrm{F}^{+} \mathrm{CD} 11 \mathrm{c}^{+}$) were identified based on the gating strategy depicted in Figure 1(a) [24]. Interestingly, as seen in BAL, a strong accumulation of eosinophils was observed following the OVA challenge (ova-ova) but the two strains showed again no 
TABLE 1: March1 does not affect eosinophilic airway inflammation but induces neutrophilic inflammation in the airways: Total inflammatory cells in bronchoalveolar lavage (BAL) fluid were counted using hemocytometer and trypan blue exclusion method. Differential cell count in BAL: Differential cell count was performed on BAL cells adhered to slides and stained with HEMA-3. For each sample, 200-300 cells were counted under the microscope (40x), and their percentage was multiplied by the total cell count to extrapolate absolute differential count. ${ }^{*}$ and ${ }^{* * *}$ denote statistically significant; ${ }^{*} p<0.1$ (trend); N.S.: non-ignificant. Data are presented as median (nonparametric data) and pooled from 5 independent experiments. $N=9-12$ /group.

\begin{tabular}{|c|c|c|c|c|c|c|c|}
\hline & \multicolumn{2}{|c|}{$\begin{array}{c}\text { WT median } \\
\text { cells } \times 10^{4}\end{array}$} & \multirow{2}{*}{$\begin{array}{c}p \text { value WT sal-ova } \\
\text { versus ova-ova }\end{array}$} & \multicolumn{2}{|c|}{$\begin{array}{l}\text { March } 1^{-/-} \text {median } \\
\text { cells } \times 10^{4}\end{array}$} & \multirow{2}{*}{$\begin{array}{c}p \text { value March1 } 1^{-l-} \\
\text { sal-ova versus } \\
\text { ova-ova }\end{array}$} & \multirow{2}{*}{$\begin{array}{c}p \text { value ova-ova } \\
\text { WT versus } \\
\text { ova-ova March } 1^{-/-}\end{array}$} \\
\hline & sal-ova & ova-ova & & sal-ova & ova-ova & & \\
\hline Total cells/mouse BAL & 6 & 15.9 & $0.09 \#$ & 4 & 15.7 & $<0.001^{* * *}$ & N.S. \\
\hline Mono/macs & 5.16 & 4.9 & N.S. & 3.7 & 4.7 & N.S. & N.S. \\
\hline Lymphocytes & 0 & 0.24 & $0.06 \#$ & 0.01 & 0.28 & $0.06 \#$ & N.S. \\
\hline Neutrophils & 0 & 0.01 & N.S. & 0 & 0.27 & $0.02^{*}$ & N.S. \\
\hline Eosinophils & 0 & 1.9 & $<0.001^{* * *}$ & 0.07 & 5.8 & $<0.001^{* * *}$ & N.S. \\
\hline
\end{tabular}

difference in the level of lung tissue eosinophilic inflammation (Figure 2(a)). Of note, a two-way ANOVA analysis of lung tissue neutrophils revealed a significant interaction between the two factors (strain and immunization), which was not the case for eosinophils, for example. All pairwise multiple comparison tests showed that neutrophil numbers in the lung tissue were significantly higher in ova-ova relative to sal-ova sham-sensitized controls within $\mathrm{March}^{-1-}$, whereas in lungs of sal-ova and ova-ova (within WT) they are not significantly different. Likewise, within sal-ova groups, lung neutrophils were lower in $\mathrm{March}^{-1-}$ than WT. Comparing neutrophils in sal-ova versus ova-ova within each strain separately indicates a consistent neutrophilia in both lung airways (BAL) and tissue of $\mathrm{March}^{-1-}$ mice but not within WT groups (Table 1 and Figure 2(b)).

As alveolar macrophages are reported to be protective in some models of asthma [25], we verified if their numbers differed between WT and March $1^{-1-}$ mice. Alveolar macrophages were identified by flow cytometry on sets of mice that did not undergo lung lavage. Figure 2(c) reveals that alveolar macrophage proportions decreased significantly in ova-ova versus sal-ova conditions for both strains, in line with the establishment of a proinflammatory environment. However, we found no difference between the two strains. Altogether, these results demonstrate that the allergic-induced change in cellular components of eosinophils and alveolar macrophages in the lung is independent of March1 expression.

\subsection{March1 Modulates Cytokine Production during Lung} Allergic Inflammation. In allergic patients and mice, the balance between Th2 CD4 T cells secreting IL-4, IL-5, IL-9, IL-10, and IL-13 and Th1 CD4 T cells secreting IFN- $\gamma$ and IL-12 is shifted towards more Th2 CD4 cells [26]. The concentrations of Th2 cytokines in lung lavage and lung tissue homogenates are also reported to be higher than Th1 cytokines in allergic inflammation $[1,27,28]$. In order to determine if the OVA-induced inflammation described above was accompanied by a rise in Th2 cytokines, we first performed intracellular staining on lung cells to identify cytokine-producing T lymphocytes (Figure 3(a)). Interestingly, although the induction of allergic asthma did not result in an accumulation of the IFN- $\gamma$-producing Th1 cells in either strain, we found significantly less of those activated CD4 $\mathrm{T}$ cells (secreting IFN- $\gamma$ ) in ova-ova March $1^{-/-}$ compared to ova-ova WT (Figure 3(b)). On the other hand, IL-5-expressing CD4 T cells were significantly higher in ova-ova compared to sal-ova controls in WT, whereas they were mildly elevated in March $1^{-/-}$ova-ova compared to their controls (sal-ova) $(p<0.1)$ (Figure 3(c)). However, the ratio of IL-5 over IFN- $\gamma$-expressing $\mathrm{CD}^{+}$cells in the lung was significantly higher in ova-ova compared to shamsensitized and challenged (sal-ova) in both strains, without difference between WT and KO (Figure 3(d)).

Another Th2 cytokine of interest is IL-13, which is responsible for airway remodeling, including mucus production [29], and contributes to the inflammatory response [30]. We found that IL-13-producing $\mathrm{T}$ cells were significantly higher in lungs of ova-ova group compared to the controls (sal-ova) in WT but not in March1 ${ }^{-1-}$ groups (Figure 3(e)). Further, IL- $13^{+} \mathrm{CD} 4 \mathrm{~T}$ cells in ova-ova WT group were also significantly higher than in March $1^{-/-}$mice counterparts (ova-ova) (Figure 3(e)). Interestingly, the pattern of IL-13 in lung homogenates was in conformity with that of the intracellular staining results of $\mathrm{CD}^{+}$producing IL-13, confirming the effect of March1 on this Th2 cytokine (Figures 3(e) and 4(a)). Altogether, these data demonstrate a Th2 bias in this model and suggest that March1 is required to maximize a Th2-skewed immune response and cytokine profile.

To extend our analysis, we measured protein levels of other cytokines in lung homogenates. In line with a Th2skewed response in this allergic model, IL-4 in lung tissue homogenates was also significantly higher in ova-ova compared to sal-ova conditions for WT and $\mathrm{March}^{-1-}$ mice. However, we could not observe a difference between the two strains (Figure 4(b)). The immunosuppressive cytokine IL-10 is produced by all subtypes of T cells, as well as B cells and myeloid cells [31]. Our results show that in lung homogenates, IL-10 concentrations tended to be diminished in ova-ova versus sal-ova in March $1^{-1-}$ but not in WT mice (Figure $4(\mathrm{c})$ ). Further, for the ova-ova groups, IL-10 was significantly less in $\mathrm{March}^{-1-}$ than WT mice (Figure 4(c)). 


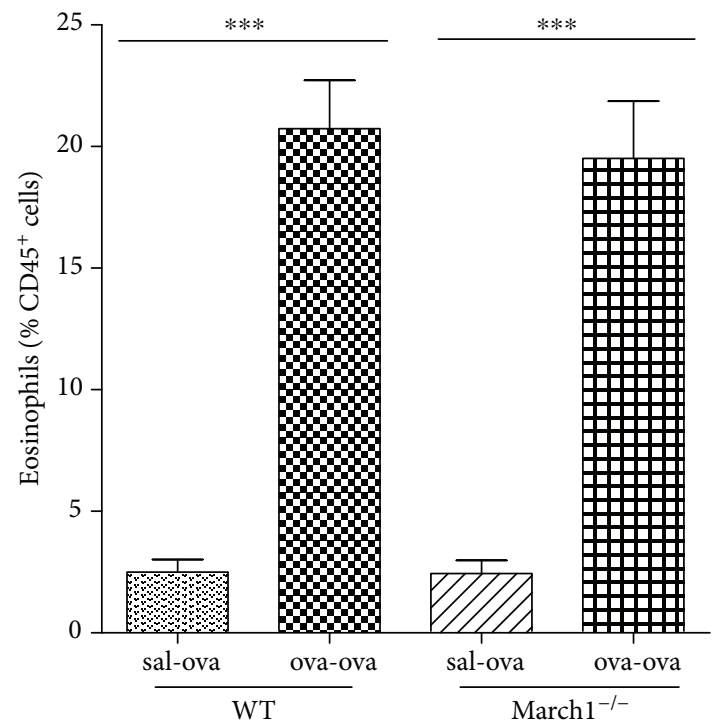

(a)

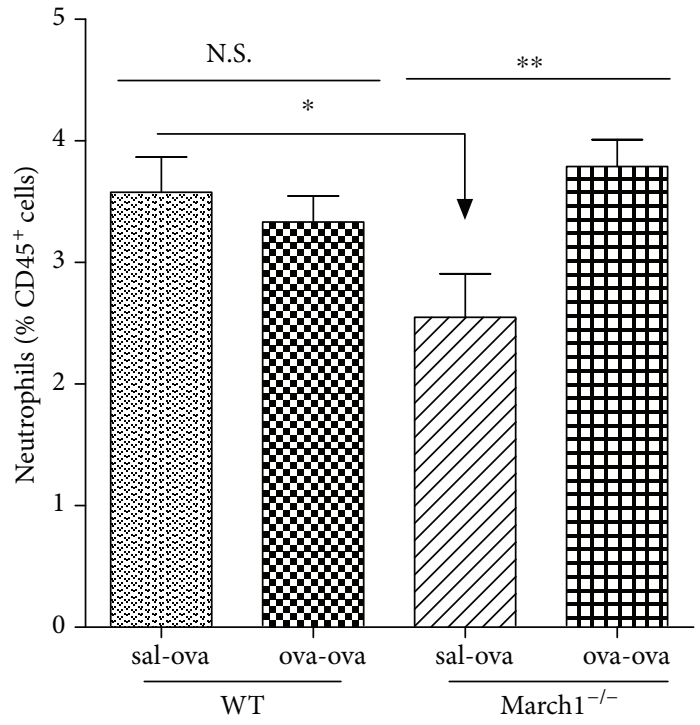

(b)

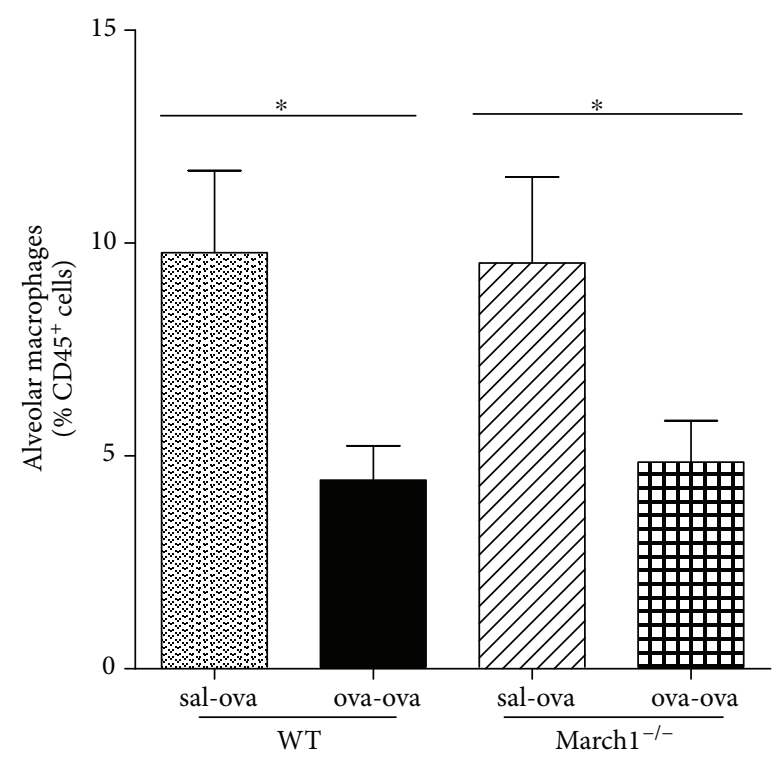

(c)

FIGURE 2: March1 does not affect allergic-induced eosinophilic recruitment or alveolar macrophages inflammatory dynamics in lung tissue. Lung immune cells were isolated by digestion and eosinophils (a), neutrophils (b), and alveolar macrophages (c) were analyzed by flow cytometry according to the gating strategy depicted in Figure 1(a). Cell numbers were normalized as percentage of $\mathrm{CD}_{4} 5^{+}$immune cells. ${ }^{*} p<0.05,{ }^{* *} p<0.01,{ }^{* * *} p<0.001$. Data are pooled from 5 independent experiments and presented as mean with SEM; $n=8-12$ /group.

We also tested the presence of two proinflammatory cytokines (IL- 6 and TNF- $\alpha$ ) in lungs. IL- 6 is produced by a wide variety of cell types and is known to contribute to Th2 cytokine production, lung eosinophilia, and airway hyperresponsiveness [32]. As such, it was found to be higher in serum of asthmatic patients [33,34] and mice [32]. In our study, as expected, IL-6 was significantly higher in lung homogenates from ova-ova WT group compared to the salova controls. However, in March1 $1^{-1-}$ mice, the IL-6 levels were low in both groups and were not affected by prior ova sensitization (Figure 4(d)). For TNF- $\alpha$, which is known to contribute to several features of OVA-induced allergic airway inflammation [35], we observed an increase in ova-ova versus sal-ova controls both in WT and $\mathrm{March}^{-1-}$ mice but without any significant difference between the two strains (Figure 4(e)). Altogether, these results suggest that March1 differentially impacts certain cytokines that are known to contribute to the establishment of allergic asthma in the OVA model.

3.4. March1 Regulates the Production of OVA-Specific Immunoglobulins (Igs). An increase in total $\mathrm{IgE}$ as well as antigen-specific $\operatorname{IgE}$ and $\operatorname{IgG}_{1}$ antibodies is considered one of the hallmarks of the Th2 response leading to allergic 


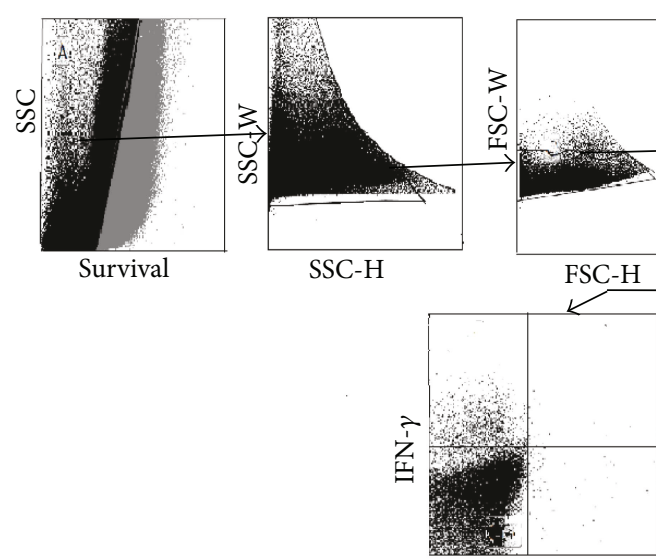

Isotype Ctrl-IL-13

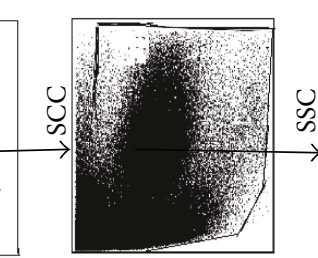

FSC

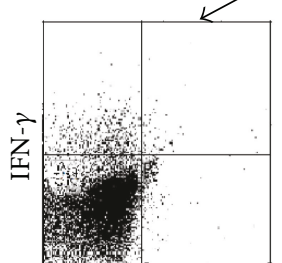

IL-13

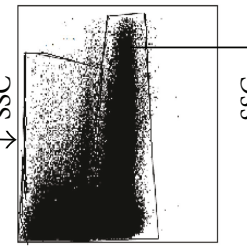

CD45

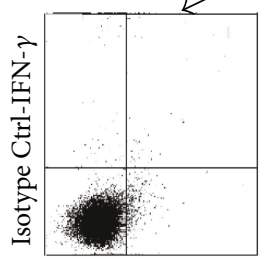

Isotype Ctrl-IL-5
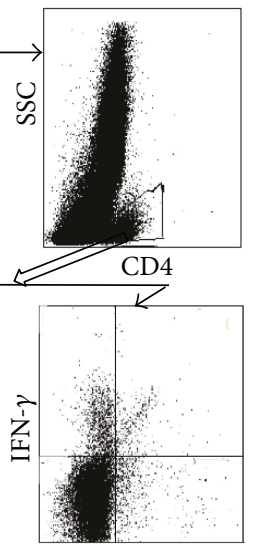

IL-5

(a)

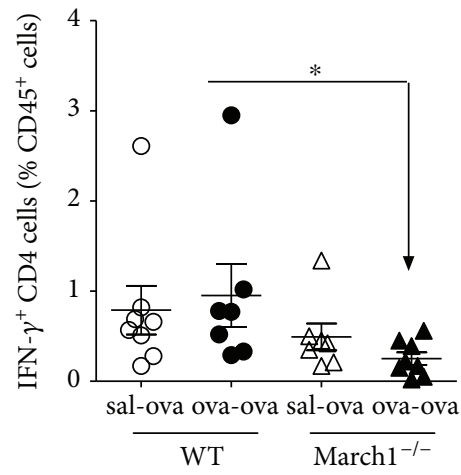

(b)

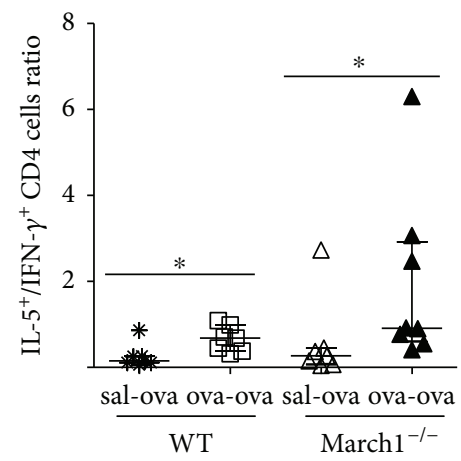

(d)

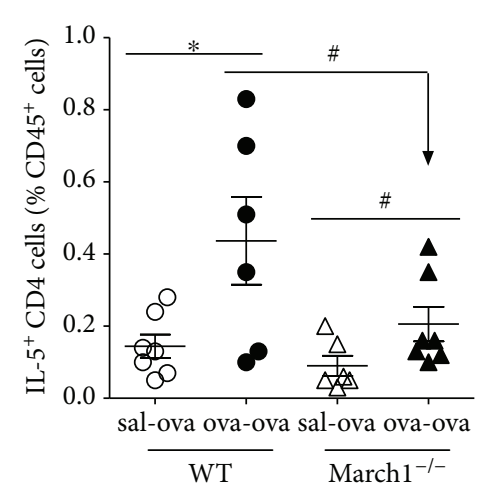

(c)

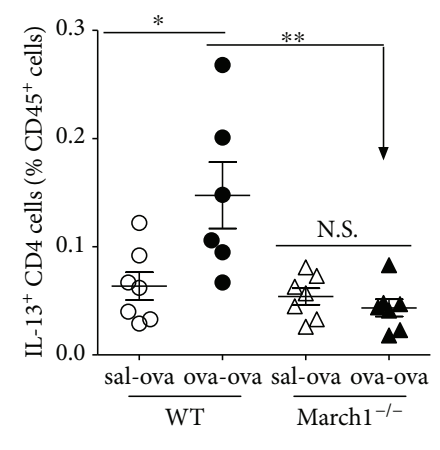

(e)

Figure 3: March1 deficiency is associated with less IFN- $\gamma$-, IL-5-, and IL-13-producing Th cells in the ovalbumin-allergic model. Lung immune cells were isolated by digestion and stained for surface CD45 and CD4 (a). Then, cells were permeabilized and stained for IFN- $\gamma$ (b), IL-5 (c), and IL-13 (e). Gating strategy of lung cell subpopulations (a), IFN- $\gamma$-producing CD4 cells (b), IL-5-producing CD4 cells (c), ratio of IL-5/IFN- $\gamma$ CD4 T cells (d), and IL-13-producing CD4 cells (e); all normalized and expressed as \% of CD45 ${ }^{+}$immune cells. ${ }^{*} p<0.05,{ }^{* *} p<0.01,{ }^{*} p<0.1$ (trend). Data are pooled from 3 independent experiments and presented in means with SEM (b, c) or medians with interquartile (d, e); $n=6-8$ /group.

asthma [36]. Total IgE and OVA-specific IgE and $\operatorname{IgG}_{1}$ were measured in serum. As compared to control mice, Ova sensitization and challenge resulted in a significant increase in seric total IgE concentrations in WT and March $1^{-1-}$ mice (Figure 5(a)). However, the IgE concentrations tended to be less for ova-ova March1 ${ }^{-/-}$mice compared to their WT counterparts (Figure 5(a)). Interestingly, while both the Ova-specific IgEs and IgG1s were increased in the ova-ova groups (versus sal-ova within each strain), March1 was needed to obtain a maximal accumulation of OVA-specific IgEs (Figures 5(b) and 5(c)). These results suggest that that March1 somehow affects class-switching events and/or antibody generation. As antibody production is dependent on antigen presentation in secondary lymphoid organs, we tested the efficiency of OVA presentation in vitro using splenocytes from immunized animals. As judged by the 


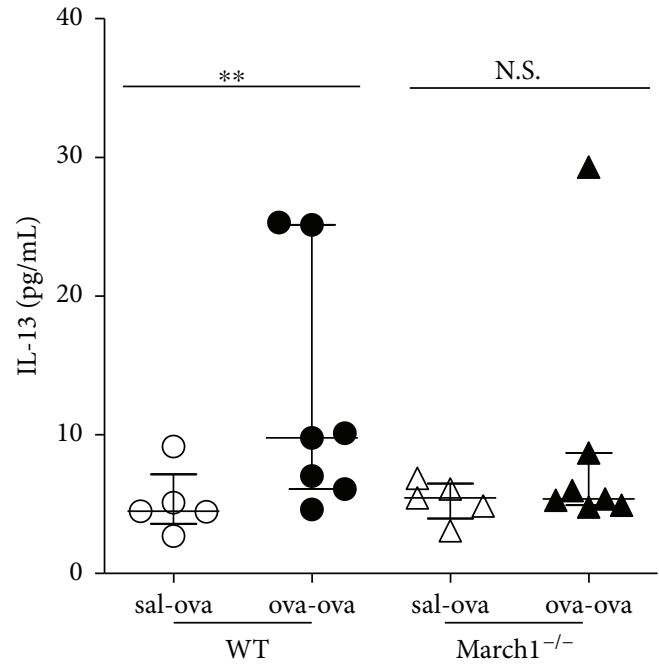

(a)

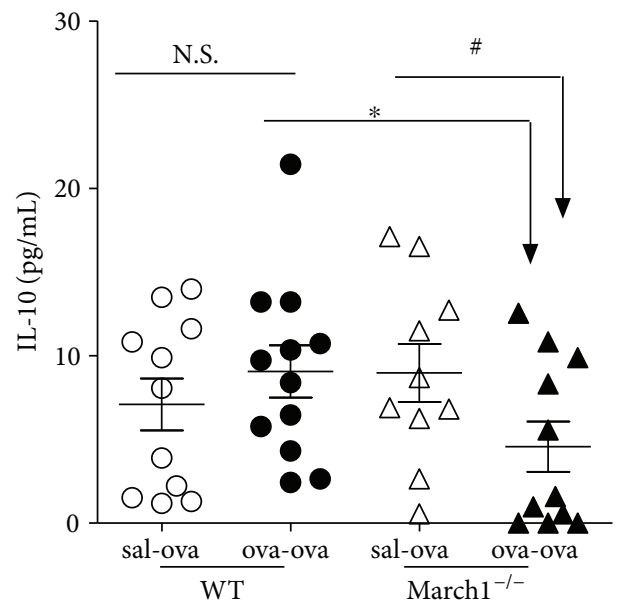

(c)

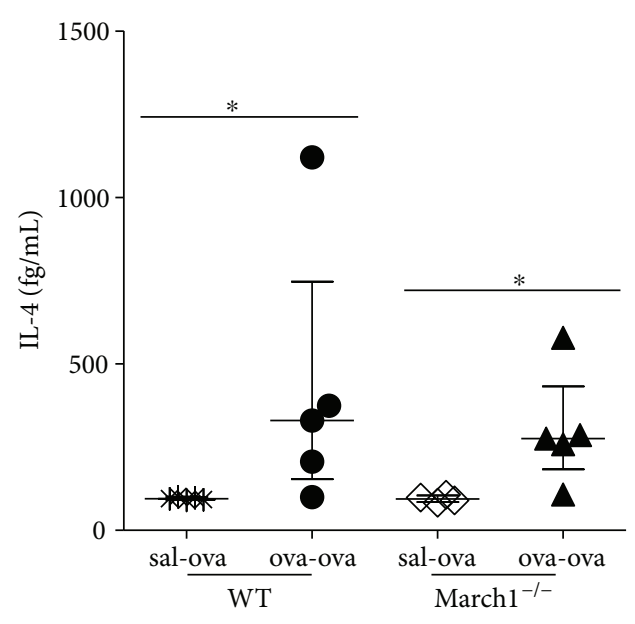

(b)

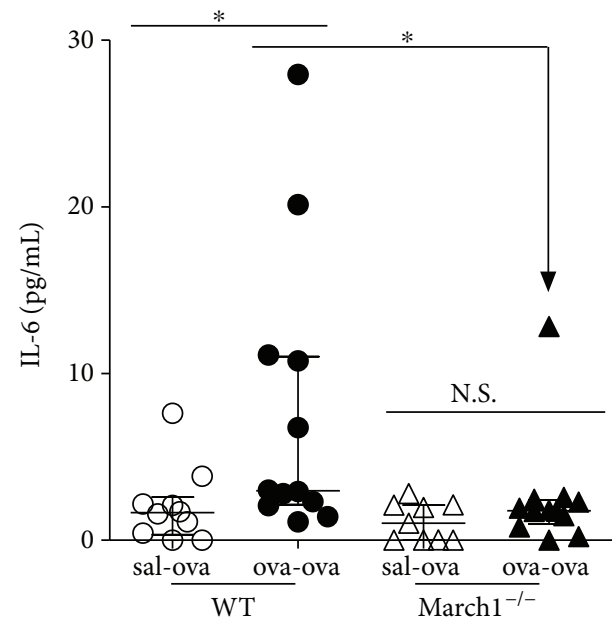

(d)

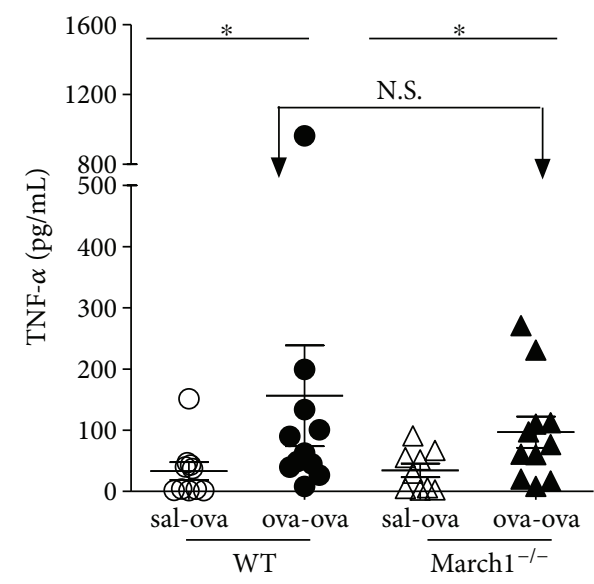

(e)

Figure 4: March1 deficiency is associated with less IL-13, IL-10, and IL-6 in lungs of OVA-sensitized and challenged mice. IL-13 (a), IL-4 (b), IL-10 (c), IL-6 (d), and TNF- $\alpha$ (e) cytokines were measured in lung homogenates using an enhanced sensitivity cytometric bead array (CBA). ${ }^{*} p<0.05,{ }^{* *} p<0.01,{ }^{\#} p<0.1$ (trend), N.S.: nonsignificant. Data are pooled from several independent experiments and presented in median with interquartile values (a, b, d) or in mean with SEM (c, e); $n=5-7$ (a, b), $n=9-12$ (c, d, e). 


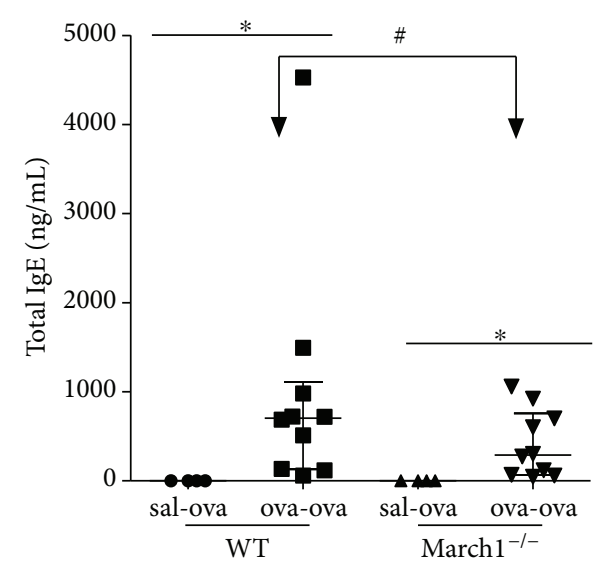

(a)

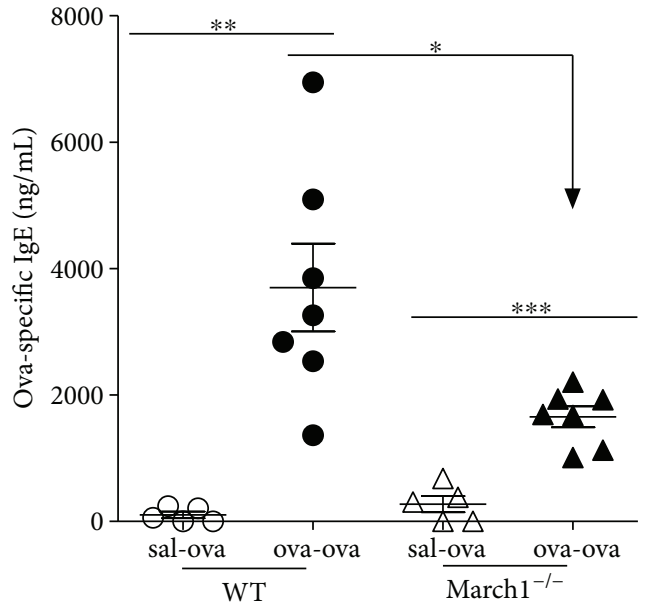

(b)

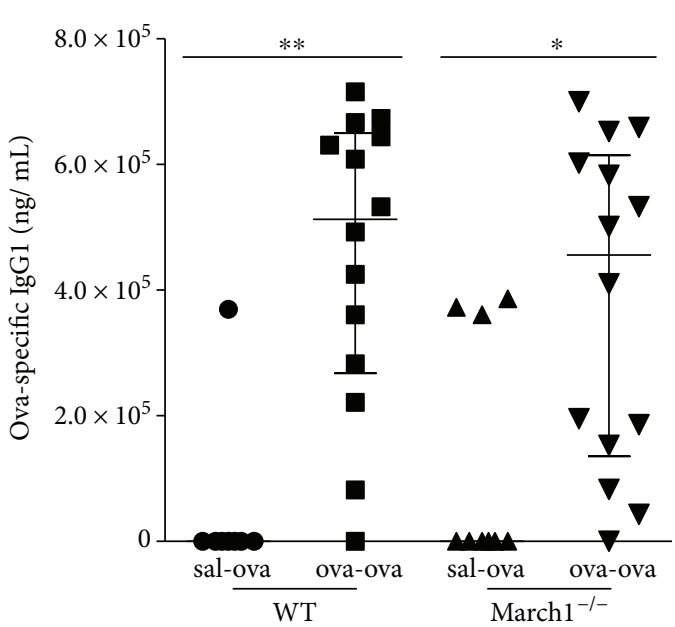

(c)

Figure 5: March1 deficiency leads to less antibody production against OVA in the ovalbumin-allergic model. Total IgE (a), OVA-specific IgE (b), and OVA-specific $\operatorname{IgG}_{1}$ (c) were measured in the serum of WT and March1 $1^{-1-}$ mice. ${ }^{*} p<0.05,{ }^{* *} p<0.01,{ }^{* * *} p<0.001,{ }^{\#} p<0.1$ (trend). Data are pooled from 4 independent experiments and presented as mean with SEM (a, b); $n=4-7$. In (c) (IgG1), data are pooled from 7 independent experiments and presented as median with interquartile values; $n=8-14$.

IFN- $\gamma$ production, our results showed an increased $\mathrm{T}$ cell activation in response to exogenously added OVA protein in all mice that have been sensitized and challenged in vivo (Figure 6(a)). Further, IL-5 level in supernatant of splenocyte cultures from ova-ova March $1^{-l-}$ mice tended to be less than in WT ova-ova, in consistency with the lower level of IL- $5^{+}$ CD4 cells in lungs of March1 $1^{-1-}$ mice (Figure 6(b)). Interestingly, the OVA-induced IL-10 production was also reduced in splenocytes from March1-deficient mice, again, in line with the reduced IL-10 concentrations in lungs of March1 $1^{-/-}$ova-ova mice (Figure 6(c)). Altogether, these results suggest a role for March1 in the mucosal response to antigens and in maximizing Th2 cytokines.

3.5. March1 Modulates C5aR (CD88) Expression by Alveolar Macrophages and Lymphocytes. $\operatorname{IgG}_{1}$ antibodies play a key role in allergic asthma through activation of complement [36]. As March1 regulates the display of various transmembrane proteins at the plasma membrane, and given the established proinflammatory role of the complement by-product,
C5a, in allergic asthma [36-38], we wondered if March1 could modulate the complement receptor (C5aR; CD88) expression in lung inflammatory cells as potential pathway in modulating allergic reactions. Therefore, we assessed CD88 expression by flow cytometry on lung inflammatory cells gated as in Figures 1(a) (myeloid cells) and 7(a) (lymphoid cells). OVA challenge of immunized mice resulted in switch of significant portion of $\mathrm{CD}^{+} 8^{+}$alveolar macrophages from $\mathrm{CD} 88^{\mathrm{Hi}}$ to $\mathrm{CD} 88^{\text {int }}$ expressing cells in both strains; however, CD88 ${ }^{\text {int }}$ alveolar macrophages, which significantly increased in ova-ova versus sal-ova within each strain, tended to be less in ova-ova March $1^{-1-}$ relative to ova-ova WT (Figure 7(b)).

Since CD88 is known to be expressed mainly by myeloid cells, and to less extent by lymphocytes [39], it was not surprising in our study to find higher number of $\mathrm{CD} 88^{+}$ alveolar macrophages (about two- to threefold more) compared to $\mathrm{CD} 88^{+}$lymphocytes. The proportions of $\mathrm{CD} 88^{+}$ lymphocytes increased with OVA challenge of immunized mice in both strains, but only in B cells and $\mathrm{CD}^{-} \mathrm{CD}^{+}$ 


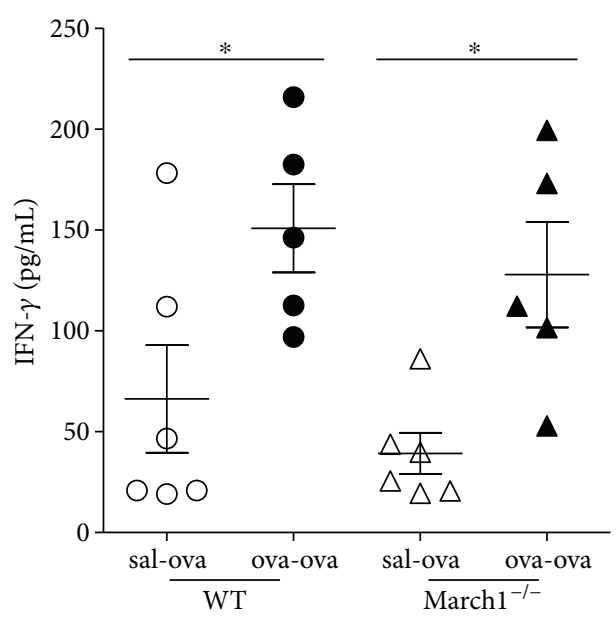

(a)

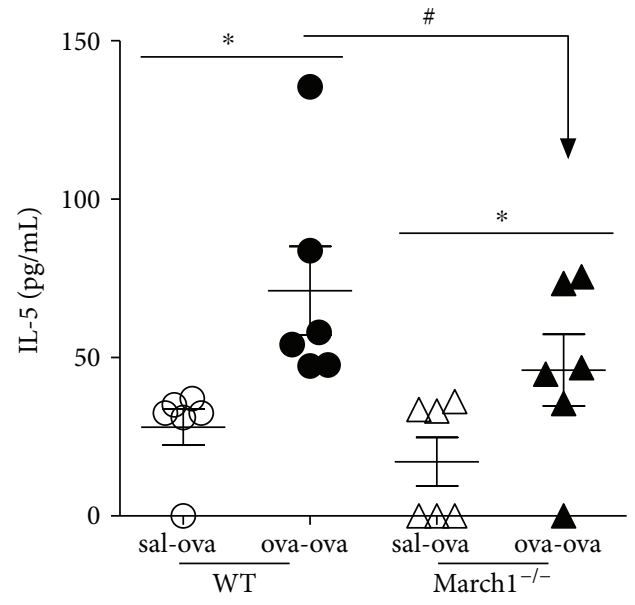

(b)

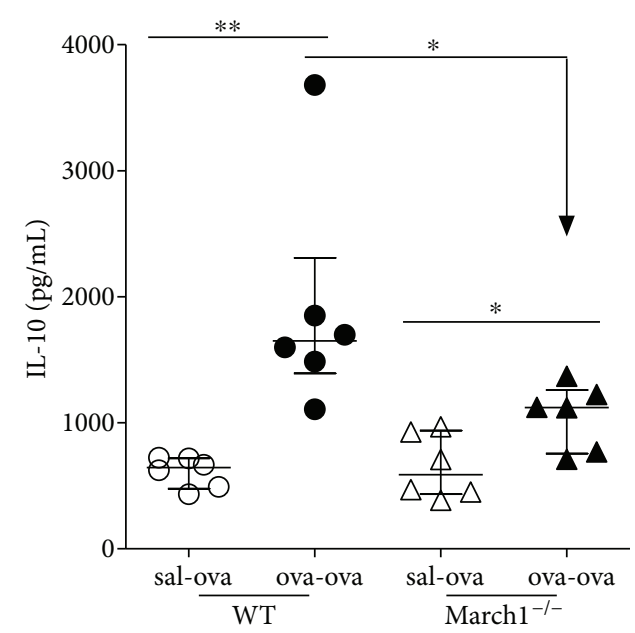

(c)

FIGURE 6: March1deficiency is associated with downregulation of IL-10 production. Splenocytes were isolated and cultured for 3 days with $1 \mathrm{mg} / \mathrm{mL}$ OVA. Supernatants were collected and assayed for IFN- $\gamma$ (a), IL-5 (b), and IL-10 (c). * and ** denote statistically significant. ${ }^{\#} p<0.1$ (trend). Data are pooled from 3 independent experiments and presented as mean with SEM; $n=6-8 /$ group.

cells this increase was significant; whereas $\mathrm{CD} 8^{+} \mathrm{CD} 4^{-} \mathrm{T}$ cells and B lymphocytes in March $1^{-1-}$ ova-ova tended to be lower compared to ova-ova WT (Figure $7(\mathrm{c})$ ), in consistency with the pattern of CD88 ${ }^{\text {int }}$ alveolar macrophages (Figure 7(b)), suggesting an overall lower positive and expression of CD88 by both alveolar macrophages and lymphocytes in March1-deficent mice.

\subsection{March1 Enhances OVA-Induced Airway} Hyperresponsiveness without Affecting Mucus Production. Increased airway responsiveness to nonspecific stimuli, such as methacholine, is one of the hallmarks of an asthmatic reaction and can be measured in C57BL/6 mice [20, 23, 40]. In the present study, airway resistance was found to be significantly different among the experimental groups at each dose of methacholine challenge (two-way ANOVA test) (Figure $8(\mathrm{a})$ ). By isolating and testing groups at each dose, airway resistance in March1 $1^{-1-}$ (ova-ova) at $25 \mathrm{mg}$ dose was significantly less than WT (ova-ova), $p<0.05$, $t$-test. Further, comparing airway resistance between ova-ova groups in the two strains over doses of methacholine by two-way repeated measure ANOVA revealed that airway resistance tended to be different between the two strains $(p=0.059)$. All pairwise multiple comparison procedure confirmed that airway resistance is significantly lower in March $1^{-1-}$ relative to WT at $25 \mathrm{mg} / \mathrm{mL}$ dose of methacholine challenge $(p<0.01)$ (Figure $8(b))$.

Mucus production in the lung airways is another important hallmark of asthma $[41,42]$. To determine if it is affected by March1 deficiency, we quantified mucus-secreting cells in lung tissues. Our results show that OVA sensitization greatly increased the number of mucus-producing cells in response to the OVA challenge but there was no difference in the magnitude of the response between WT and $\mathrm{March}^{-/-}$mice (Figures 9(a) and 9(b)).

3.7. Decreased Serum IgE and Lung IL-6 in March1 ${ }^{-1-}$ ovaova Is MHC II Ubiquitination Independent. We asked whether the lower levels of IgE and IL-6 in March1 ${ }^{-/-}$are due to the upregulated surface expression of MHC II, caused 


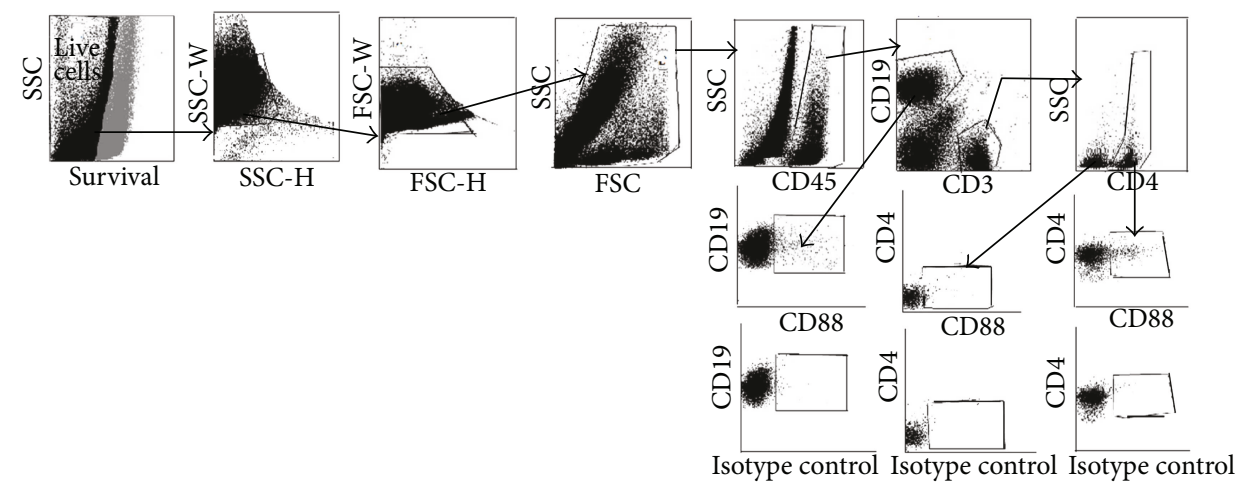

(a)

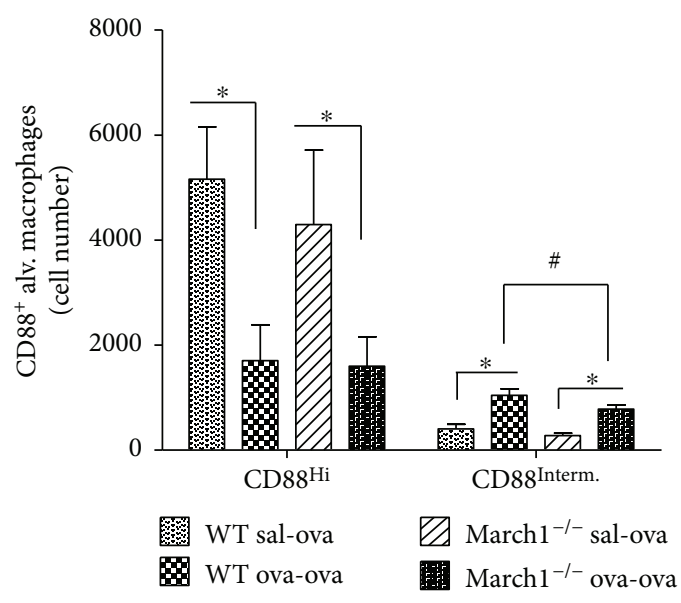

(b)

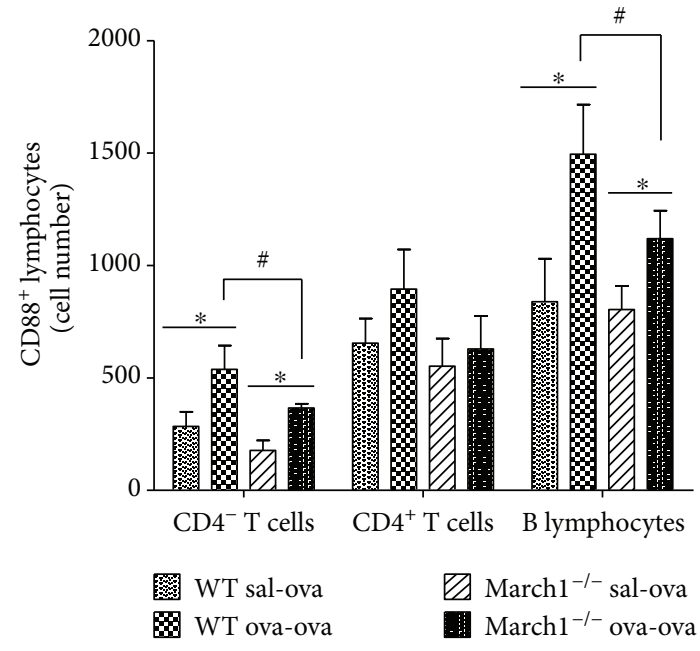

(c)

FIgure 7: The OVA challenge of immunized mice is associated with an increase in the number of lung CD88 Interm. alveolar macrophages and CD88-positive lymphocytes relative to sham-sensitized groups in the two strains, the magnitude of which is reduced in the absence of March1. CD88-expressing lung lymphocytes were identified by flow cytometry (a). Alveolar macrophages were identified as in Figure 1(a). The numbers of $\mathrm{CD} 88^{\mathrm{Hi}}$ and CD88 $8^{\mathrm{Interm}}$ alveolar macrophages were expressed as absolute numbers (b). Absolute numbers of CD88-positive T cells and B lymphocytes are shown in (c). ${ }^{*}$ denotes statistically significant, ${ }^{\#} p<0.1$ (trend). Data are pooled from 3 independent experiments and presented as mean with SEM; $n=5-8 /$ group.

by diminished ubiquitiniation by March1 or due to a different immune function. To address this question, we sensitized and challenged sets of WT and March1 $1^{-1-}$ mice as well as MHC II knock-in (MHCII KI) mice (in which March1 is intact but the MHC II beta chain is mutated, preventing ubiquitination) [43]. We observed that $\operatorname{IgE}$ and IL-6 in ova-ova-treated MHCII KI mice were comparable to ova-ova WT and both WT and MHCII KI (ova-ova) are higher than $\mathrm{March}^{-1-}$ (ova-ova) (Figures 10(a) and 10(b)). These MHCII KI mice, just like March1 $1^{-1-}$, express more class II molecules at the surface of B cells (Figure 10(c)). However, they express CD86 to the same level as WT cells (Figure 10(d)). These results suggest that the increase in MHC II expression observed in March $1^{-1-}$ mice is not sufficient to negatively regulate IgE and IL-6 production.

\section{Discussion}

IL-10, a potent regulatory cytokine, induces March1 expression in monocytes, macrophages, and DCs [9, 10, 44]. March1, through its ubiquitin ligase activity, displays immuneregulatory properties through downregulation of MHC II surface expression $[9,45]$. The effect of MHC II ubiquitination on antigen presentation was studied by different groups using March1-deficient mice and MHCII knock-in mice (in which the sole MHCII $\beta$ chain cytoplasmic lysine residue is mutated), resulting in conflicting findings (reviewed in [46]. Work by Ohmura-Hoshino et al. demonstrated that although loss of MHC II ubiquitination increased antigen presentation, it decreased the capacity of March1 KO and MHCII KI DCs to stimulate naïve $\mathrm{T}$ cell activation and differentiation in vitro due to downregulation of LFA-1 [7, 43]. However, McGehee et al. reported that MHCII ubiquitination in BM-DCs is not necessary for stimulation of OVA-specific $\mathrm{T}$ cells ex vivo [47]. Due to the broad expression of MHC II in multiple cell types during many cellular processes, it is important to evaluate the impact of Marchl deficiency in the context of a Th2-mediated disease, such as allergic asthma.

Our results show that in all conditions, the expression of MHCII remains lower in WT APCs as compared to their 


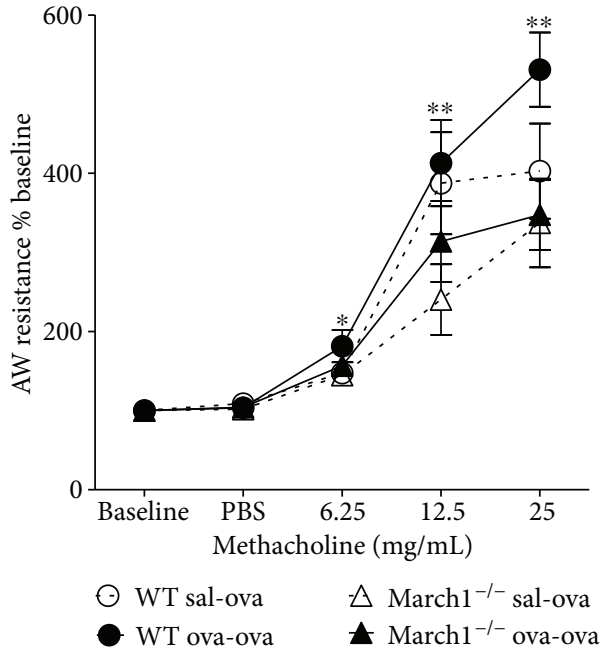

(a)

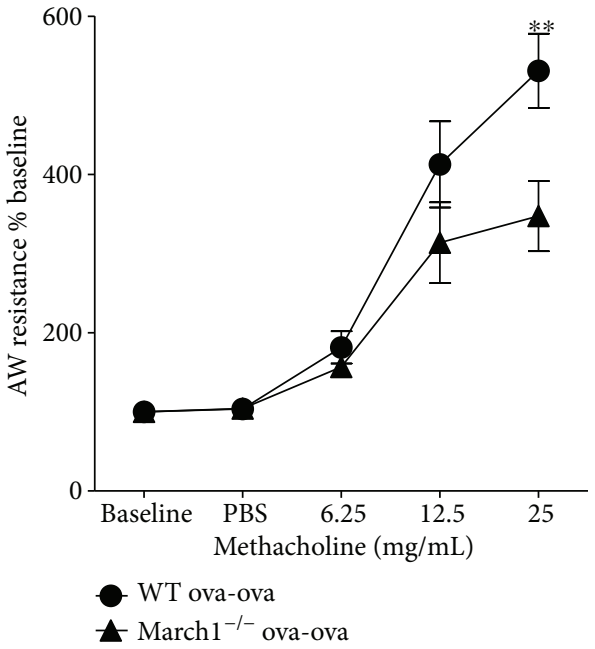

(b)

FIGURE 8: March1 enhances airway hyperreactivity in lungs of OVA-sensitized and challenged mice in the ovalbumin-allergic model. Mice underwent methacholine challenge by administration of gradual 3 doses of methacholine intranasally while they are under mechanical ventilation and airway resistance in WT and March $1^{-l-}$ were recorded, extrapolated, and plotted (a). Airway resistance as \% base for ova-ova groups in WT and March $1^{-/-}$was also plotted separately (b). Dotted line in (a) represents sal-ova and solid line represents ovaova. ${ }^{*}$ and ${ }^{* *}$ in (a) denote statistically significant for strain factor by 2 -way ANOVA at each dose. In (b), ${ }^{* *}$ denotes significant difference between ova-ova WT versus ova-ova $\mathrm{KO}$ at $25 \mathrm{mg} / \mathrm{mL}$ dose of methacholine. Data are pooled from 5 independent experiments and presented as means with SEM; $n=8-9$ /group. Further details on statistical analysis are laid out in the text.

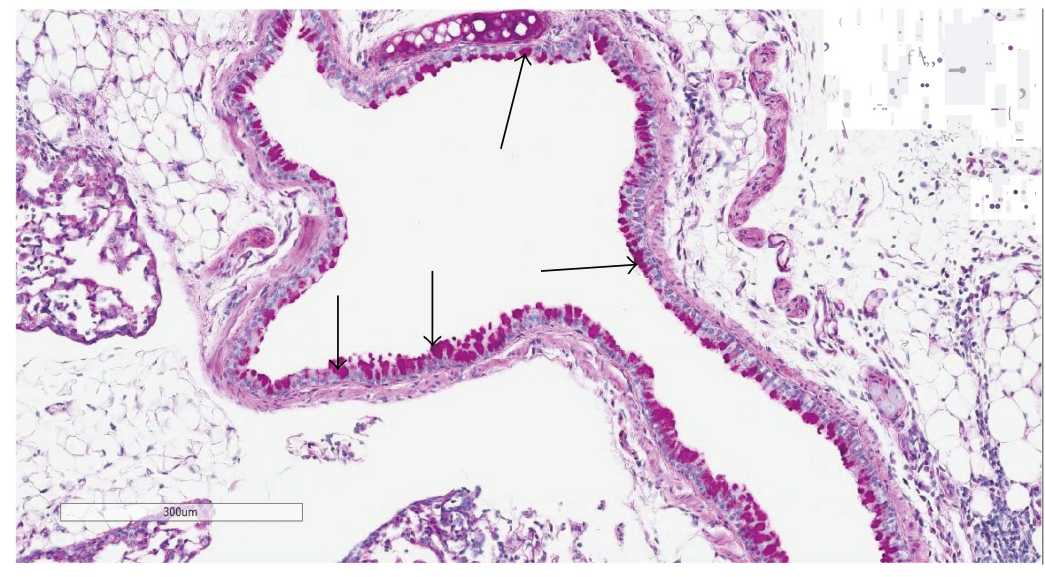

(a)

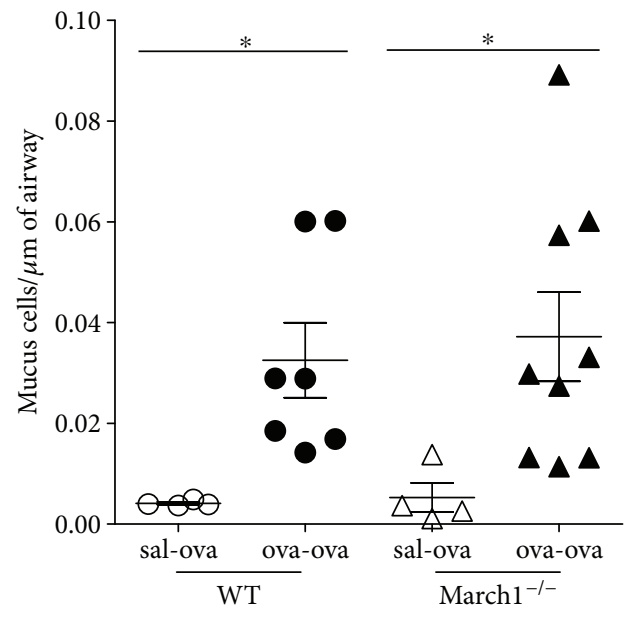

(b)

Figure 9: March1 does not affect mucus production in allergic model of lung inflammation. Lungs were fixed, embedded in paraffin, sectioned, and stained with PAS for mucus evaluation. (a) Representative image from WT (ova-ova) group. Pink cells along the circumference of airways were counted and expressed as number of cells/ $\mu \mathrm{m}$ of airway perimeter and plotted in panel (b). ${ }^{*}$ denotes statistically significant. Data are pooled from 3 independent experiments and presented as means with SEM; $n=4$ (sal-ova), $n=7-9$ (ova-ova).

March $1^{-l-}$ counterparts. This demonstrates that March1 expression is not downmodulated by the ova sensitization and challenge in WT animals. Interestingly, such strong MHCII expression in March1-deficient mice did not exacerbate allergic asthma. While eosinophilic inflammation and mucus production were induced to a similar extent in $\mathrm{March}^{-/-}$and WT mice, neutrophilic inflammation was more prominent in March $1^{-1-}$ relative to WT. Airway hyperresponsiveness, another hallmark of allergic asthma, was reduced in the absence of March1. Thus, one possibility to investigate in the future is that the increased expression of both MHCII and CD86 in March1-deficient mice blunts the $\mathrm{Th}_{2}$ response to the allergen and/or activates Th17 cells, which are known to increase neutrophil influx in airways of mice with allergic asthma [48]. Our results suggest a protective role of March1 from lung neutrophilic inflammation in allergic asthma.

IFN- $\gamma$ is a Th1 cytokine, reported to suppress allergic reaction by a variety of mechanisms such as regulating allergen presentation to T lymphocytes, enhancing differentiation 


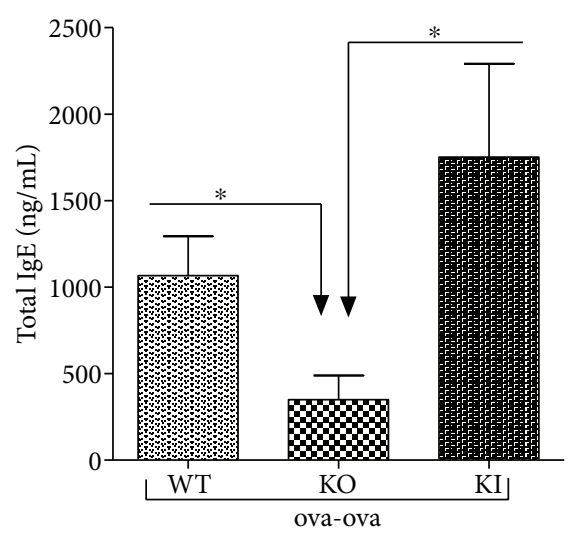

(a)

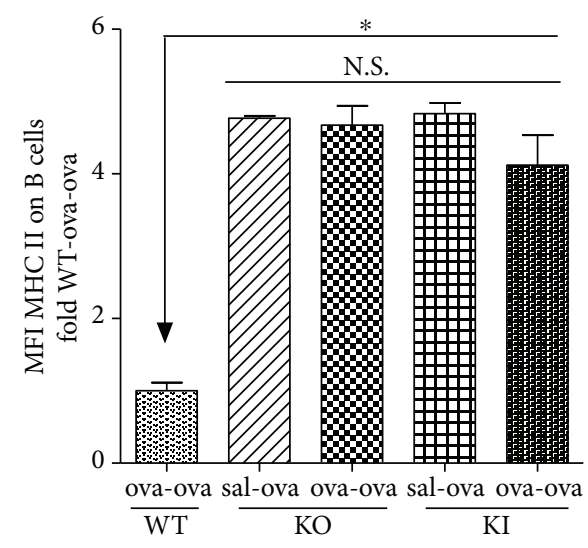

(c)

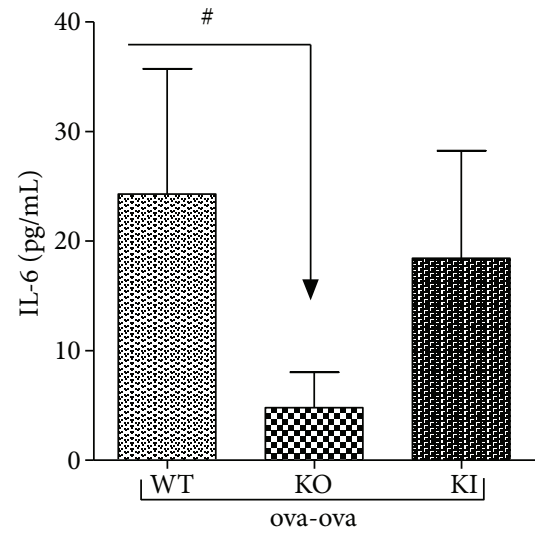

(b)

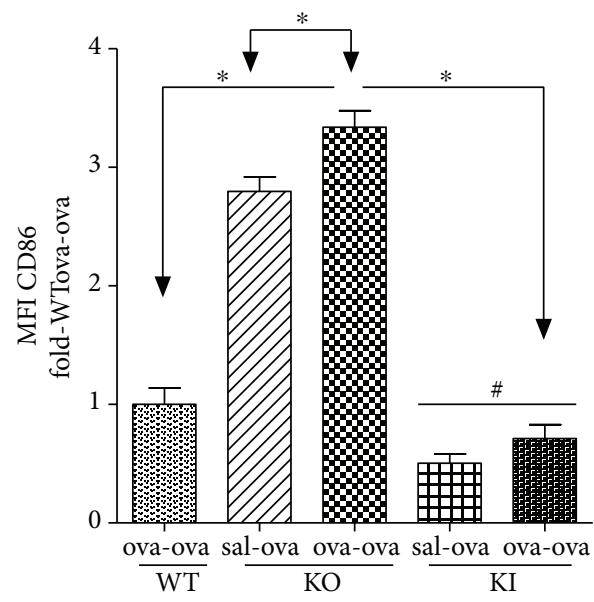

(d)

FIGURE 10: Decreased serum IgE, IL-13, and IL-6 in lungs of March $1^{-1-}$ mice is not dependent on MHC II ubiquitination. Total serum IgE (a) and IL-6 in lung homogenates (b) were measured in ova-sensitized and challenged mice. Lung B cells were gated as in Figure 1(a) and the expression of MHC II (c) and CD86 (d) was assessed. ${ }^{*}$ denotes statistically significant, \# $p<0.1$ (trend). Data are pooled from 2 independent experiments and presented as means with SEM; $n=4$-5/group.

of naïve T lymphocytes into Th1, and inhibition of Th2 lymphocyte differentiation and suppression of Th2 cytokine release from Th2 activated cells [49]. Based on our results of less IFN- $\gamma$ in March $1^{-1-}$ and given that IFN- $\gamma$ is a pleiotropic cytokine, it is apparent that the immune-suppressive function of INF- $\gamma$ does not explain the lower level of this Th1 cytokine in March1-deficient mice. Since INF- $\gamma$ regulates MHC II expression in different cell populations $[50,51]$, we speculate that its effector function in March1deficient mice, which exhibited milder reaction in allergic and cytokine responses compared to $\mathrm{WT}$, implicates regulation of MHC II expression by immune and nonimmune lung cells [52]. Future studies are needed to further explore the role of IFN- $\gamma$ in this context.

Of note, March1-deficient T cells produced less IL-10, in line with the reduced levels of IL-10 detected in lungs of asthmatic March $1^{-1-}$ mice. IL-10 has been reported to promote the development of allergen-induced smooth muscle hyperresponsiveness in $\mathrm{C} 57 \mathrm{BL} / 6$ mice [53]. Interestingly, this could be due to the reduced IL-13 levels found in the lungs of March1 KO mice. Indeed, IL-10 production was shown to be reduced in Th2 cultures from IL-13-deficient mice [54]. Multiple mechanisms have been evoked to explain how IL-13 can increase and IFN- $\gamma$ can downmodulate inflammation of the airways $[49,55]$. IL-13 plays a critical role in allergies and exogenous IL-13 can induce AHR in absence of T and B cells [56,57]. Further, it was previously found that AHR failed to develop in ovalbumin- sensitized and challenged mice deficient in IL-13, despite the robust Th2-biased pulmonary eosinophil response $[56,58]$. Thus, the lower level of IL-10 and IL-13 may contribute to the mild airway hyperresponsiveness in $\mathrm{March}^{-1-}$ compared to $\mathrm{WT}$ mice. The fact that this decrease in airway resistance in $M a r c h 1^{-/-}$is evident (statistically significant) at a dose of $25 \mathrm{mg} / \mathrm{kg}$ methacholine can be attributed to one or both of the following reasons. First, C57BL/6 strain of mice is known to exhibit less AHR in an allergen model compared to other strains such as BALB/C [20], which poses limitation on studying this parameter and demands trying other strains and/or model modifications. To our knowledge, March1 deficiency has, so far, only been studied in the C57BL/6 background. Future studies should use BALB/C mice as a 
strain, more prone to AHR. Second, $25 \mathrm{mg} / \mathrm{kg}$ methacholine dose could be the optimum dose to reach detectable difference in airway resistance between WT and $\mathrm{March}^{-1-}$ in C67BL/6 mice in this experimental setting.

An important issue for future studies will be to determine how the lack of March1 can modulate IL-13 production. As March1-deficient DCs were previously shown to produce aberrant cytokine profiles in response to TLR stimulation, the Th1/Th2 balance may be perturbed following OVA presentation. IL-13 is also produced by innate lymphoid cells (nuocytes, ILC2s), which express MHC class II and help shape $\mathrm{T}$ cell responses that control airway inflammation $[59,60]$. Future studies should investigate their levels of March1 and how this ubiquitin ligase can potentially modulate the production of IL-13 or their capacity to trigger a Th2 type of response. Indeed, a March1-triggered reduced ligand density on ILC2s and professional APCs would limit TCR engagement and predispose for differentiation of Th2 cells $[13,61]$. In support of this notion, a recent study using an in vivo model of allergy reported that limiting MHC II expression to DCs impairs the ability of the host to develop Th2 allergic immune response [62].

The CD88 complement receptor (C5aR) is a G-proteincoupled receptor, expressed mainly in myeloid cells and has been reported as a therapeutic target, which blockade reduced airway inflammatory cell and cytokine responses in OVA-murine model of allergic asthma [63]. It is stimulated by the complement by-product, C5a, which has multiple proinflammatory effector functions as reviewed before [36]. C5a, along with the other anaphylatoxin, C3a, is well known to be potent proinflammatory mediators contributing to allergic reactions through a variety of immune functions [64]. For example, C5a is chemoattractant for inflammatory cells (macrophages, neutrophils, basophils, and mast cells) [65]. Further, airway hyperreactivity, in IgG immune complex-induced acute lung injury, was reported to be C5 and $\mathrm{C} 5 \mathrm{a}$ dependent [66]. Thus, lower CD88-expressing alveolar macrophages, $\mathrm{CD} 4^{-} \mathrm{T}$ cells, and B lymphocytes in ovaova $\mathrm{March}^{-1-}$ relative to $\mathrm{WT}$ in our study may further explain and contribute to the milder airway hyperresponsiveness in March $1^{-1-}$ mice.

Another feature of asthma in mice [67] and humans, to be addressed and thought about in future studies, in relevance to $\mathrm{IL}-13$ in March1 $\mathrm{KO}$ mice in this model is subepithelial lung fibrosis [41]. IL-13 is a potent activator of collagen production by fibroblasts in mice and human cells $[56,68]$. Our results suggest that March $1^{-/-}$mice may exhibit less asthma-associated subepithelial lung fibrosis. In support of this notion, IL-6, a profibrotic cytokine in asthma model [41] was also lower in March1 ${ }^{-/-}$ova-ova. Whether this suggested protection from subepithelial lung fibrosis and from lung neutrophilic inflammation are related remains a valid question to be investigated for further characterization of March1's role in the immune disorder of allergic asthma.

March1 deficiency had a strong impact on the antibody response. We observed lower levels of total and ova-specific $\mathrm{IgE}$ and $\mathrm{IgG}_{1}$ in sera of March1 $1^{-/-}$mice relative to WT. As both IL-13 and IL-4 promotes IgE class switching
[69], the lower IgE levels in March1 ${ }^{-/-}$could be attributed to less IL-13 in March1 $1^{-1-}$ mice.

We observed that IgE and IL-6 in KI mice were comparable to ova-ova WT and both WT and KI (ova-ova) are higher than March1 $1^{-1-}$ (ova-ova), suggesting that these effects are due to March1's activity on other targets (Figures 10(a) and 10(b)). This conclusion further confirms that other immune functions of March1 (beyond ubiquitination of MHC II) are more important in modulating the allergic reactions in this model.

In conclusion, we show here in this study that March1 E3 ubiquitin ligase contributes to the development of allergic inflammatory response by promoting Th2 cytokines, particularly those implicated in IgE class switching and airway hyperresponsiveness (IL-13). Our study also suggests that March1 promotes allergic reactions via enhancing the allergen-induced expression of complement receptor CD88 by inflammatory cells. This study also suggests that March1 can dually play a protective role from lung neutrophilic inflammation in allergic asthma. The conclusion of this study is expected to better direct future studies towards therapeutic targets for March1 in disease models and subsequent clinical perspectives.

\section{Abbreviations}

March1: Membrane-associated Ring CH 1

OVA: Ovalbumin

APCs: Antigen-presenting cells

DCs: Dendritic cells

BAL: Bronchoalveolar lavage

CBA: Cytometric bead array.

\section{Conflicts of Interest}

No financial and commercial conflicts of interest to declare.

\section{Authors' Contributions}

Osama A. Kishta designed and performed the experiments. Antoine Sabourin, Leora Simon, Toby McGovern, Maxime Raymond, Tristan Galbas, and Abdelilah Majdoubi performed experiments. Osama A. Kishta, Antoine Sabourin, Leora Simon, Toby McGovern, Maxime Raymond, Tristan Galbas, Abdelilah Majdoubi, James G. Martin, and Jacques Thibodeau analyzed data. Satoshi Ishido provided key reagents. Osama A. Kishta and Jacques Thibodeau wrote the manuscript and all authors revised the text.

\section{Acknowledgments}

The authors thank Serge Sénéchal and Dr Armelle Le campion for technical and training support with flow cytometry. The authors acknowledge the help of M. Miguel Chagnon ( $U$ of $M$, Department of Mathematics and Statistics) for helping with the statistical analysis. This work was supported by a grant to Jacques Thibodeau from the Canadian Institutes for Health Research (MOP 136802) and the Canadian Foundation for Innovation (30017). 
Osama A. Kishta and Abdelilah Majdoubi were supported by fellowships from Saputo. Jacques Thibodeau holds the Saputo Research Chair.

\section{References}

[1] L. Cohn, J. A. Elias, and G. L. Chupp, "Asthma: mechanisms of disease persistence and progression," Annual Review of Immunology, vol. 22, no. 1, pp. 789-815, 2004.

[2] K. Corcoran, M. Jabbour, C. Bhagwandin, M. J. Deymier, D. L. Theisen, and L. Lybarger, "Ubiquitin-mediated regulation of CD86 protein expression by the ubiquitin ligase membraneassociated RING-CH-1 (MARCH1)," Journal of Biological Chemistry, vol. 286, no. 43, pp. 37168-37180, 2011.

[3] K. J. Cho, E. Walseng, S. Ishido, and P. A. Roche, "Ubiquitination by March-I prevents MHC class II recycling and promotes MHC class II turnover in antigen-presenting cells," Proceedings of the National Academy of Sciences of the United States of America, vol. 112, no. 33, pp. 10449-10454, 2015.

[4] Y. Matsuki, M. Ohmura-Hoshino, E. Goto et al., "Novel regulation of MHC class II function in B cells," The EMBO Journal, vol. 26, no. 3, pp. 846-854, 2007.

[5] S. Ishido, Y. Matsuki, E. Goto, M. Kajikawa, and M. OhmuraHoshino, "MARCH-I: a new regulator of dendritic cell function," Molecules and Cells, vol. 29, no. 3, pp. 229-232, 2010.

[6] E. Walseng, K. Furuta, B. Bosch et al., "Ubiquitination regulates MHC class II-peptide complex retention and degradation in dendritic cells," Proceedings of the National Academy of Sciences of the United States of America, vol. 107, no. 47, pp. 20465-20470, 2010.

[7] R. Ishikawa, M. Kajikawa, and S. Ishido, "Loss of MHC II ubiquitination inhibits the activation and differentiation of CD4 T cells," International Immunology, vol. 26, no. 5, pp. 283-289, 2014.

[8] S. K. Mittal, K. J. Cho, S. Ishido, and P. A. Roche, "Interleukin 10 (IL-10)-mediated immunosuppression: March-1 induction regulates antigen presentation by macrophages but not dendritic cells," Journal of Biological Chemistry, vol. 290, no. 45, pp. 27158-27167, 2015.

[9] J. Thibodeau, M. C. Bourgeois-Daigneault, G. Huppe et al., "Interleukin-10-induced MARCH1 mediates intracellular sequestration of MHC class II in monocytes," European Journal of Immunology, vol. 38, no. 5, pp. 1225-1230, 2008.

[10] L. E. Tze, K. Horikawa, H. Domaschenz et al., "CD83 increases MHC II and CD86 on dendritic cells by opposing IL-10driven MARCH1-mediated ubiquitination and degradation," Journal of Experimental Medicine, vol. 208, no. 1, pp. 149165, 2011.

[11] J. Oh, N. Wu, G. Baravalle et al., "MARCH1-mediated MHCII ubiquitination promotes dendritic cell selection of natural regulatory T cells," Journal of Experimental Medicine, vol. 210, no. 6, pp. 1069-1077, 2013.

[12] G. Chattopadhyay and E. M. Shevach, "Antigen-specific induced $t$ regulatory cells impair dendritic cell function via an IL-10/MARCH1-dependent mechanism," The Journal of Immunology, vol. 191, no. 12, pp. 5875-5884, 2013.

[13] P. N. van, F. Klauschen, and R. N. Germain, "T-cell-receptordependent signal intensity dominantly controls $\mathrm{CD} 4^{+} \mathrm{T}$ cell polarization in vivo," Immunity, vol. 41, no. 1, pp. 63-74, 2014.

[14] J. Paez-Cortez, R. Krishnan, A. Arno et al., "A new approach for the study of lung smooth muscle phenotypes and its application in a murine model of allergic airway inflammation," PLoS One, vol. 8, no. 9, article e74469, 2013.

[15] M. Starkhammar, O. Larsson, G. S. Kumlien et al., "Toll-like receptor ligands LPS and poly (I:C) exacerbate airway hyperresponsiveness in a model of airway allergy in mice, independently of inflammation," PLoS One, vol. 9, no. 8, article e104114, 2014.

[16] K. H. Shalaby, T. Jo, E. Nakada et al., "ICOS-expressing CD4 $\mathrm{T}$ cells induced via TLR4 in the nasal mucosa are capable of inhibiting experimental allergic asthma," The Journal of Immunology, vol. 189, no. 6, pp. 2793-2804, 2012.

[17] J. G. Martin, H. R. Campbell, H. Iijima et al., "Chlorineinduced injury to the airways in mice," American Journal of Respiratory and Critical Care Medicine, vol. 168, no. 5, pp. 568-574, 2003.

[18] L. Piccotti, B. F. Dickey, and C. M. Evans, "Assessment of intracellular mucin content in vivo," in Methods in Molecular Biology (Methods and Protocols), M. McGuckin and D. Thornton, Eds., vol. 842, pp. 279-295, Humana Press, New York, NY, USA, 2012.

[19] P. J. Busse, J. M. Birmingham, A. Calatroni et al., "Effect of aging on sputum inflammation and asthma control," The Journal of Allergy and Clinical Immunology, vol. 139, no. 6, pp. 1808-1818.e6, 2017.

[20] M. M. Gueders, G. Paulissen, C. Crahay et al., "Mouse models of asthma: a comparison between C57BL/6 and BALB/c strains regarding bronchial responsiveness, inflammation, and cytokine production," Inflammation Research, vol. 58, no. 12, pp. 845-854, 2009.

[21] R. K. Kumar, C. Herbert, and P. S. Foster, "The "classical" ovalbumin challenge model of asthma in mice," Current Drug Targets, vol. 9, no. 6, pp. 485-494, 2008.

[22] E. Bartee, M. Mansouri, B. T. Hovey Nerenberg, K. Gouveia, and K. Fruh, "Downregulation of major histocompatibility complex class I by human ubiquitin ligases related to viral immune evasion proteins," Journal of Virology, vol. 78, no. 3, pp. 1109-1120, 2004.

[23] T. Morokata, J. Ishikawa, K. Ida, and T. Yamada, "C57BL/6 mice are more susceptible to antigen-induced pulmonary eosinophilia than $\mathrm{BALB} / \mathrm{c}$ mice, irrespective of systemic T helper 1/T helper 2 responses," Immunology, vol. 98, no. 3, pp. 345-351, 1999.

[24] C. U. Duerr, C. D. McCarthy, B. C. Mindt et al., "Type I interferon restricts type 2 immunopathology through the regulation of group 2 innate lymphoid cells," Nature Immunology, vol. 17 , no. 1, pp. $65-75,2016$.

[25] Z. Zaslona, S. Przybranowski, C. Wilke et al., "Resident alveolar macrophages suppress, whereas recruited monocytes promote, allergic lung inflammation in murine models of asthma," The Journal of Immunology, vol. 193, no. 8, pp. 4245-4253, 2014.

[26] Q. Hamid and M. Tulic, "Immunobiology of asthma," Annual Review of Physiology, vol. 71, no. 1, pp. 489-507, 2009.

[27] A. Ray and L. Cohn, "Th2 cells and GATA-3 in asthma: new insights into the regulation of airway inflammation," The Journal of Clinical Investigation, vol. 104, no. 8, pp. 985993, 1999.

[28] S. Romagnani, "The role of lymphocytes in allergic disease," The Journal of Allergy and Clinical Immunology, vol. 105, no. 3, pp. 399-408, 2000. 
[29] L. Whittaker, N. Niu, U. A. Temann et al., "Interleukin-13 mediates a fundamental pathway for airway epithelial mucus induced by CD4 T cells and interleukin-9," American Journal of Respiratory Cell and Molecular Biology, vol. 27, no. 5, pp. 593-602, 2002.

[30] M. W. Kinyanjui, J. Shan, E. M. Nakada, S. T. Qureshi, and E. D. Fixman, "Dose-dependent effects of IL-17 on IL-13induced airway inflammatory responses and airway hyperresponsiveness," The Journal of Immunology, vol. 190, no. 8, pp. 3859-3868, 2013.

[31] C. M. Hawrylowicz and A. O'Garra, "Potential role of interleukin-10-secreting regulatory $\mathrm{T}$ cells in allergy and asthma," Nature Reviews Immunology, vol. 5, no. 4, pp. 271283, 2005.

[32] M. Rincon and C. G. Irvin, "Role of IL-6 in asthma and other inflammatory pulmonary diseases," International Journal of Biological Sciences, vol. 8, no. 9, pp. 1281-1290, 2012.

[33] A. Yokoyama, N. Kohno, S. Fujino et al., "Circulating interleukin-6 levels in patients with bronchial asthma," American Journal of Respiratory and Critical Care Medicine, vol. 151, no. 5, pp. 1354-1358, 1995.

[34] I. Tillie-Leblond, P. Gosset, A. Janin, F. Salez, L. Prin, and A. B. Tonnel, "Increased interleukin- 6 production during the acute phase of the syndrome of episodic angioedema and hypereosinophilia," Clinical \& Experimental Allergy, vol. 28, no. 4, pp. 491-496, 1998.

[35] S. Nakae, C. Lunderius, L. H. Ho, B. Schafer, M. Tsai, and S. J. Galli, "TNF can contribute to multiple features of ovalbumininduced allergic inflammation of the airways in mice," The Journal of Allergy and Clinical Immunology, vol. 119, no. 3, pp. 680-686, 2007.

[36] M. K. Pandey, "Molecular basis for downregulation of C5amediated inflammation by IgG1 immune complexes in allergy and asthma," Current Allergy and Asthma Reports, vol. 13, no. 6, pp. 596-606, 2013.

[37] R. Baelder, B. Fuchs, W. Bautsch et al., "Pharmacological targeting of anaphylatoxin receptors during the effector phase of allergic asthma suppresses airway hyperresponsiveness and airway inflammation," The Journal of Immunology, vol. 174, no. 2, pp. 783-789, 2005.

[38] S. K. Wust, M. N. Blumenthal, E. O. Corazalla, B. A. Benson, and A. P. Dalmasso, "Complement in asthma: sensitivity to activation and generation of $\mathrm{C} 3 \mathrm{a}$ and $\mathrm{C} 5 \mathrm{a}$ via the different complement pathways," Translational Research, vol. 148, no. 4, pp. 157-163, 2006.

[39] S. M. Drouin, J. Kildsgaard, J. Haviland et al., "Expression of the complement anaphylatoxin $\mathrm{C} 3 \mathrm{a}$ and $\mathrm{C} 5 \mathrm{a}$ receptors on bronchial epithelial and smooth muscle cells in models of sepsis and asthma," The Journal of Immunology, vol. 166, no. 3, pp. 2025-2032, 2001.

[40] M. J. Makela, A. Kanehiro, L. Borish et al., "IL-10 is necessary for the expression of airway hyperresponsiveness but not pulmonary inflammation after allergic sensitization," Proceedings of the National Academy of Sciences of the United States of America, vol. 97, no. 11, pp. 6007-6012, 2000.

[41] J. A. Elias, Z. Zhu, G. Chupp, and R. J. Homer, "Airway remodeling in asthma," The Journal of Clinical Investigation, vol. 104, no. 8, pp. 1001-1006, 1999.

[42] T. Aikawa, S. Shimura, H. Sasaki, M. Ebina, and T. Takishima, "Marked goblet cell hyperplasia with mucus accumulation in the airways of patients who died of severe acute asthma attack," Chest, vol. 101, pp. 916-921, 1992.
[43] M. Ohmura-Hoshino, Y. Matsuki, M. Mito-Yoshida et al., "Cutting edge: requirement of MARCH-I-mediated MHC II ubiquitination for the maintenance of conventional dendritic cells," The Journal of Immunology, vol. 183, no. 11, pp. 68936897, 2009.

[44] D. Hunt, J. E. Wilson, K. A. Weih et al., "Francisella tularensis elicits IL-10 via a $\mathrm{PGE}_{2}$-inducible factor, to drive macrophage MARCH1 expression and class II down-regulation," PLoS One, vol. 7, no. 5, article e37330, 2012.

[45] A. De Gassart, V. Camosseto, J. Thibodeau et al., "MHC class II stabilization at the surface of human dendritic cells is the result of maturation-dependent MARCH I down-regulation," Proceedings of the National Academy of Sciences of the United States of America, vol. 105, no. 9, pp. 3491-3496, 2008.

[46] J. Oh and J. S. Shin, "Molecular mechanism and cellular function of MHCII ubiquitination," Immunological Reviews, vol. 266, no. 1, pp. 134-144, 2015.

[47] A. M. McGehee, K. Strijbis, E. Guillen, T. Eng, O. Kirak, and H. L. Ploegh, "Ubiquitin-dependent control of class II MHC localization is dispensable for antigen presentation and antibody production," PLoS One, vol. 6, no. 4, article e18817, 2011.

[48] L. McKinley, J. F. Alcorn, A. Peterson et al., "TH17 cells mediate steroid-resistant airway inflammation and airway hyperresponsiveness in mice," The Journal of Immunology, vol. 181, no. 6, pp. 4089-4097, 2008.

[49] L. K. Teixeira, B. P. Fonseca, B. A. Barboza, and J. P. Viola, "The role of interferon- $\gamma$ on immune and allergic responses," Memórias do Instituto Oswaldo Cruz, vol. 100, Supplement 1, pp. 137-144, 2005.

[50] M. A. Farrar and R. D. Schreiber, "The molecular cell biology of interferon-gamma and its receptor," Annual Review of Immunology, vol. 11, no. 1, pp. 571-611, 1993.

[51] P. Frandji, C. Tkaczyk, C. Oskeritzian et al., "Presentation of soluble antigens by mast cells: upregulation by interleukin4 and granulocyte/macrophage colony-stimulating factor and downregulation by interferon- $\boldsymbol{\gamma}$," Cellular Immunology, vol. 163, no. 1, pp. 37-46, 1995.

[52] D. Gray, "Allergen-specific T-cell memory," The Lancet, vol. 353, no. 9159, pp. 1187-1188, 1999.

[53] J. P. Justice, Y. Shibata, S. Sur, J. Mustafa, M. Fan, and M. R. Van Scott, "IL-10 gene knockout attenuates allergen-induced airway hyperresponsiveness in C57BL/6 mice," American Journal of Physiology Lung Cellular and Molecular Physiology, vol. 280, no. 2, pp. L363-L368, 2001.

[54] G. J. McKenzie, A. Bancroft, R. K. Grencis, and A. N. McKenzie, "A distinct role for interleukin-13 in Th2-cellmediated immune responses," Current Biology, vol. 8, no. 6, pp. 339-342, 1998.

[55] D. A. Kuperman and R. P. Schleimer, "Interleukin-4, interleukin-13, signal transducer and activator of transcription factor 6, and allergic asthma," Current Molecular Medicine, vol. 8, no. 5, pp. 384-392, 2008.

[56] T. A. Wynn, "IL-13 effector functions," Annual Review of Immunology, vol. 21, no. 1, pp. 425-456, 2003.

[57] G. Grunig, M. Warnock, A. E. Wakil et al., "Requirement for IL-13 independently of IL-4 in experimental asthma," Science, vol. 282, no. 5397, pp. 2261-2263, 1998.

[58] D. M. Walter, J. J. McIntire, G. Berry et al., "Critical role for IL-13 in the development of allergen-induced airway hyperreactivity," The Journal of Immunology, vol. 167, no. 8, pp. 4668-4675, 2001. 
[59] L. Y. Drake, K. Iijima, and H. Kita, "Group 2 innate lymphoid cells and $\mathrm{CD}^{+} \mathrm{T}$ cells cooperate to mediate type 2 immune response in mice," Allergy, vol. 69, no. 10, pp. 1300-1307, 2014.

[60] T. Y. Halim, C. A. Steer, L. Mathä et al., "Group 2 innate lymphoid cells are critical for the initiation of adaptive $\mathrm{T}$ helper 2 cell-mediated allergic lung inflammation," Immunity, vol. 40, no. 3, pp. 425-435, 2014.

[61] C. J. Oliphant, Y. Y. Hwang, J. A. Walker et al., "MHCIImediated dialog between group 2 innate lymphoid cells and $\mathrm{CD}^{+} \mathrm{T}$ cells potentiates type 2 immunity and promotes parasitic helminth expulsion," Immunity, vol. 41, no. 2, pp. 283295, 2014.

[62] N. Niu, T. Laufer, R. J. Homer, and L. Cohn, "Cutting edge: limiting MHC class II expression to dendritic cells alters the ability to develop Th2- dependent allergic airway inflammation," The Journal of Immunology, vol. 183, no. 3, pp. 15231527, 2009.

[63] E. B. Staab, S. D. Sanderson, S. M. Wells, and J. A. Poole, "Treatment with the C5a receptor/CD88 antagonist PMX205 reduces inflammation in a murine model of allergic asthma," International Immunopharmacology, vol. 21, no. 2, pp. 293300, 2014.

[64] A. A. Humbles, C. A. Nilsson, C. Lilly et al., "A role for the C3a anaphylatoxin receptor in the effector phase of asthma," Nature, vol. 406, no. 6799, pp. 998-1001, 2000.

[65] D. Ricklin, G. Hajishengallis, K. Yang, and J. D. Lambris, "Complement: a key system for immune surveillance and homeostasis," Nature Immunology, vol. 11, no. 9, pp. 785797, 2010.

[66] N. W. Lukacs, M. M. Glovsky, and P. A. Ward, "Complementdependent immune complex-induced bronchial inflammation and hyperreactivity," American Journal of Physiology Lung Cellular and Molecular Physiology, vol. 280, no. 3, pp. L512L518, 2001.

[67] Z. Zhu, R. J. Homer, Z. Wang et al., "Pulmonary expression of interleukin-13 causes inflammation, mucus hypersecretion, subepithelial fibrosis, physiologic abnormalities, and eotaxin production," The Journal of Clinical Investigation, vol. 103, no. 6, pp. 779-788, 1999.

[68] R. Firszt, D. Francisco, T. D. Church, J. M. Thomas, J. L. Ingram, and M. Kraft, "Interleukin-13 induces collagen type1 expression through matrix metalloproteinase- 2 and transforming growth factor- $\beta 1$ in airway fibroblasts in asthma," European Respiratory Journal, vol. 43, no. 2, pp. 464-473, 2014.

[69] L. K. Poulsen and L. Hummelshoj, "Triggers of IgE class switching and allergy development," Annals of Medicine, vol. 39, no. 6, pp. 440-456, 2007. 


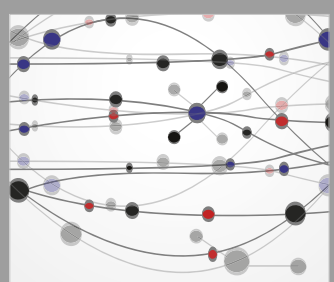

The Scientific World Journal
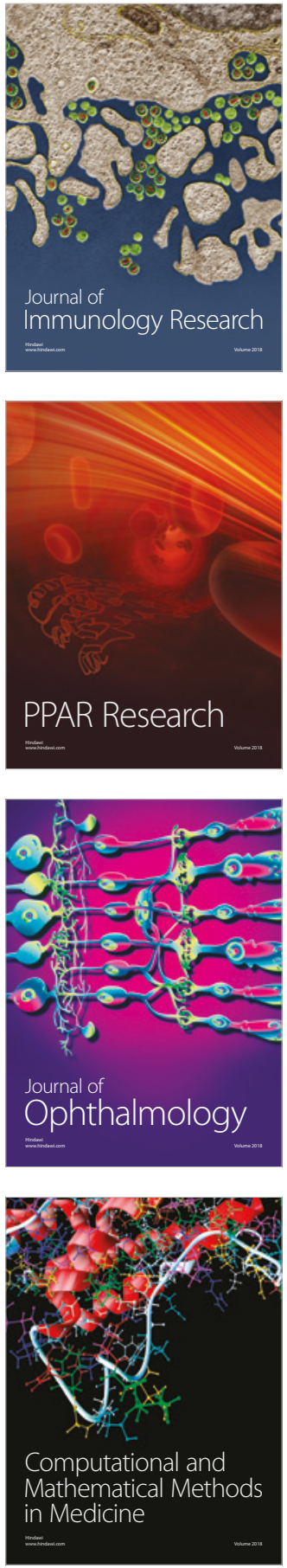

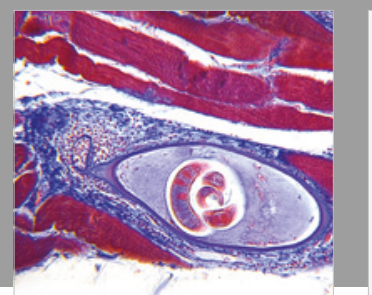

Gastroenterology Research and Practice

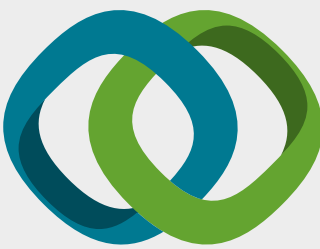

\section{Hindawi}

Submit your manuscripts at

www.hindawi.com
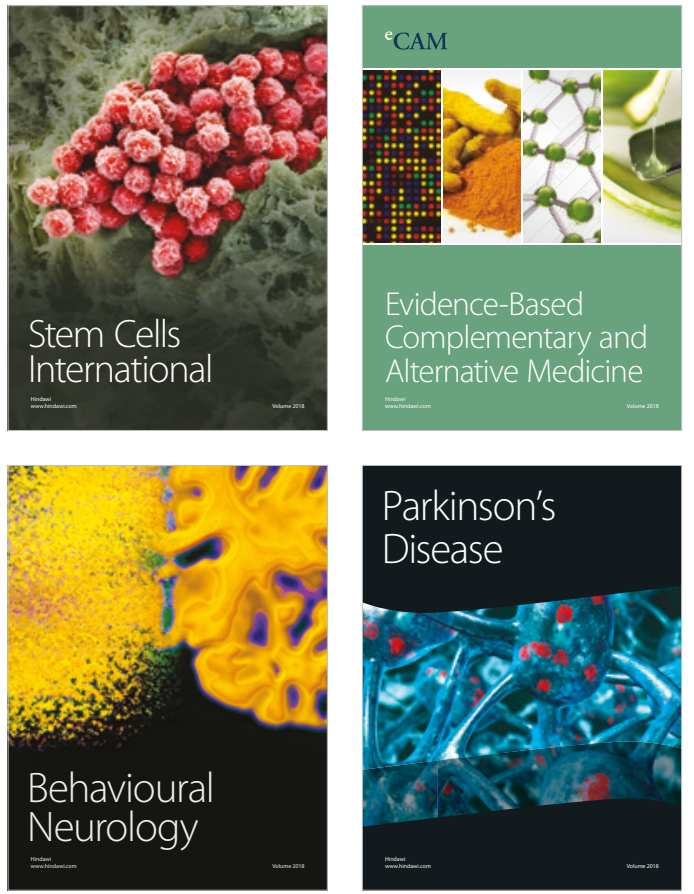

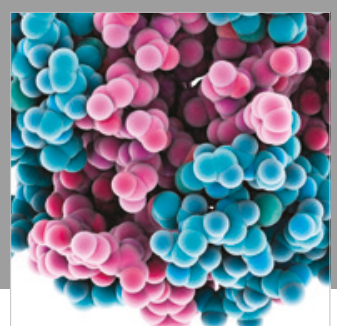

ournal of

Diabetes Research

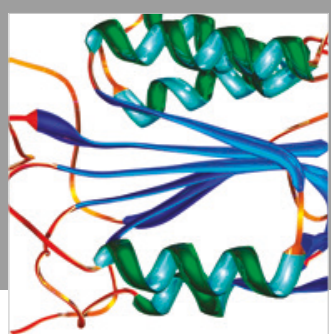

Disease Markers
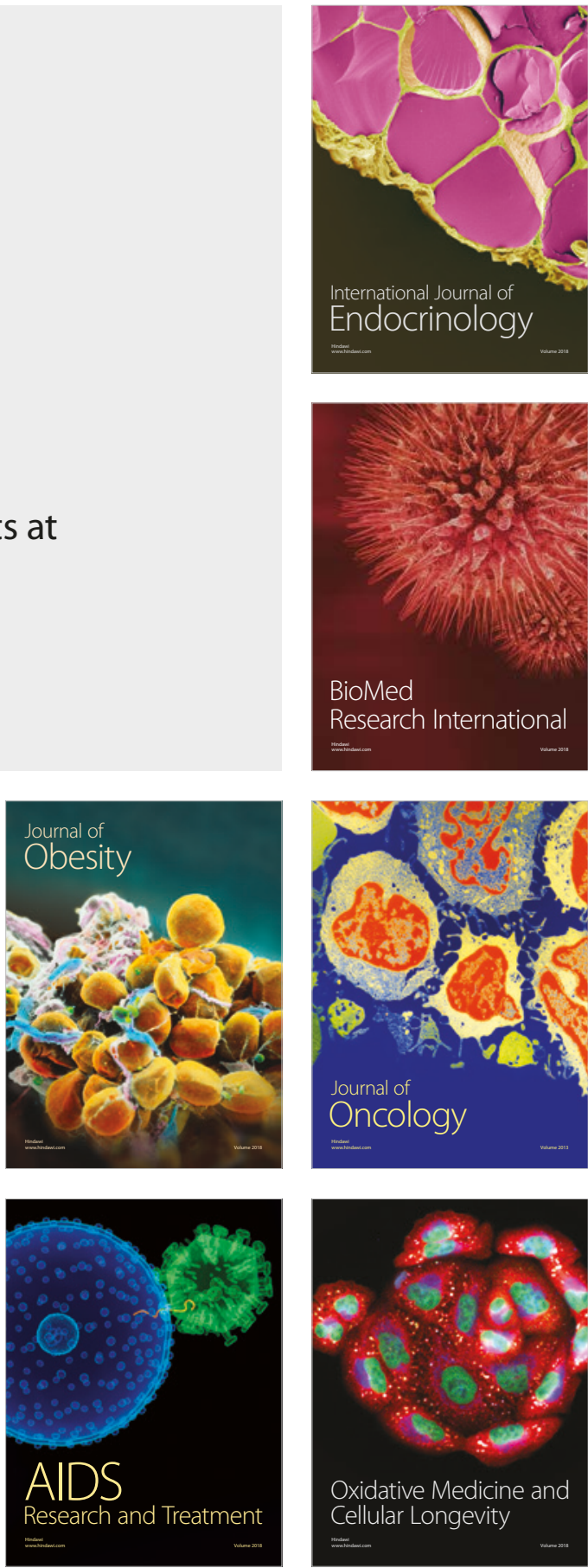